Working Paper Number: ISB-WP/101/2010

Date: July 1, 2010

ISB

\title{
Estimation of Residual Equity in Hierarchical Branding Structures: A Nonparametric Approach on Aggregate Beer Category Data
}

Sudhir Voleti

Indian School of Business

Paul Nelson

Simon Graduate School of Business, University of Rochester 


\title{
Estimation of Residual Equity in Hierarchical Branding Structures: A Nonparametric Approach on Aggregate Beer Category Data
}

\author{
Sudhir Voleti ${ }^{1}$ \\ Indian School of Business \\ Paul Nelson \\ Simon Graduate School of Business, University of Rochester

\section{Pulak Ghosh} \\ Indian Institute of Management, Bangalore.
}

\footnotetext{
${ }^{1}$ The names of the authors are arranged in the reverse alphabetical order. The corresponding author can be contacted at Sudhir_Voleti@isb.edu. The paper is based on a part of the corresponding author's doctoral thesis.
} 


\title{
Estimation of Residual Equity in Hierarchical Branding Structures: A Nonparametric Approach on Aggregate Beer Category Data
}

\begin{abstract}
Product offerings in many consumer packaged goods (CPG) categories come in a variety of complex branding structures built around some discernable branding hierarchy. We develop a nonparametric statistical method in the context of a market response model to estimate the residual equity of each hierarchical level in a typical CPG branding structure, consistent with certain economic restrictions on the equity values. Our proposed model uses readily accessible aggregate sales and product data and exploits structure inherent in the set of brand and product relations to estimate its effects on market response. We propose that established brands in mature categories must be value-enhancing and that this translates into bounds on the domain of possible brand equity values. Our model, based on a set of independent Dirichlet process priors, avoids the drawbacks inherent in alternative approaches such as fixed effects, parametric random effects and finite mixtures of continuous densities. We examine the value contribution at different levels of the branding structure and derive insights therein. We demonstrate a brand valuation procedure using a dollar metric transformation of the residual equity estimates obtained. Finally, we validate our brand valuation results with those from independent, external sources.

We test our model using AC Nielsen data on aggregate beer sales in US grocery stores. We find substantial heterogeneity in residual equity at different hierarchical levels in the branding structure, substantial differences between residual equity and more aggregate notions of brand equity and external validation of our residual equity estimates in terms of agreement with intuition, theory and previous financial data based brand equity valuations.
\end{abstract}

Keywords: Brand Equity, Brand Valuation, Dirichlet process priors, Nonparametric Bayesian Statistics. 
In an increasingly competitive marketplace, many consumer packaged goods (CPG) firms compete in portfolios of brand and product offerings. Consequently, complex branding structures involving master brands, sub-brands, umbrella brands, branded differentiators, endorsements etc (Aaker, 1991) abound. The hierarchical levels in the CPG branding structure exist presumably because firms see value in creating and keeping them. Thus, for instance, the presence of these different branding levels may aid product differentiation, renew the perceived 'freshness' of a brand, and enable appeals to heterogeneous preferences in the consumer population through a variety of line extensions, endorsements and the like (Aaker, 2004). Firms may be interested in knowing (a) what contribution each level in the branding structure brings to overall product value, and (b) precisely how much of this contribution comes from unique branding associations in order to better utilize their marketing resources and leverage their brand investments. We term the incremental contribution to product value by a particular hierarchical branding level, the aggregate 'equity' of that level. At each branding level, products may share some attributes, which also contribute to market response. Since these shared attributes are not unique to a particular product, their impact must first be removed before a 'clean' measure of equity due to unique branding associations at any hierarchical level can emerge. We term this 'clean' measure of equity the 'residual equity' for that branding level. We argue that residual equity, as opposed to more aggregated measures of equity, is often a more accurate measure of contributed product value in many marketing applications.

We view brands (and more generally, unique branding associations) as productive assets, brand equity as the notion of a return on the brand assets in terms of some observable marketing outcome(s) such as sales, price, share etc, and brand value as the net present value of a brand's equity. This paper details an approach for estimating the residual equity (henceforth, ResEqty) of each hierarchical level in the branding structure separate from other levels, using readily accessible aggregate sales data. The ResEqtys obtained are transformed into a dollar metric of earnings attributed to the brand-asset, the net 
present value of which yields brand values that are validated against information from independent external sources.

For ResEqty estimation, we consider a variety of methods. Whereas fixed effects would easily and robustly estimate the aggregate equity at any branding level, using fixed effects again to obtain ResEqty from aggregate equity would result in negative degrees of freedom ${ }^{2}$. This is because we would have a cross-sectional setting in which the number of observations (aggregate equity estimates) would be less than the number of variables (covariates for shared attributes in addition to fixed effects for ResEqty). A host of alternative approaches can be explored such as random effects (Heckman, 1982) which stochastically pools data across units but typically relies on pre-specified and potentially restrictive parametric functional forms and a finite mixture of densities (e.g., Allenby, Arora and Ginter, 1998). But these alternatives suffer from a host of problems (see, e.g., Kim, Menzefricke and Feinberg, 2004). Hence, we propose a new, flexible mixed model for ResEqty, by allowing the key equity parameters to follow an assumption-free nonparametric density specification using a Dirichlet Process (DP) prior. Our proposed DP mixture model avoids the drawbacks inherent in extant methods in that it not only flexibly approximates the target density but also endogenously determines the appropriate number of mixture components.

DP mixture models are finding use in Marketing (Braun et al., 2004; Kim et al., 2004), Statistics (Ghosh, Basu and Tiwari, 2009) and the Social networking literatures (e.g., Ghosh et al., 2009; Braun and Bonfrer, 2009). In Marketing in particular, Braun et al. (2004) use a DP prior to model the latent threshold above which insurance losses are claimed. Kim, Menzefricke and Feinberg (2004) implement a DP prior in a discrete choice model setting and demonstrate the DP mixtures' advantages over alternative finite mixture methods. In this paper, we extend the Marketing application of DP mixture models to an equity estimation setting. In doing so, we introduce three innovative modeling features. One, there are multiple hierarchical levels in the branding structure and we model each level using an independent Dirichlet process. Thus, our model incorporates and jointly estimates multiple, independent Dirichlet Processes.

\footnotetext{
${ }^{2}$ Wedel and Kamakura (1995)
} 
Two, the heterogeneity of product lines even within a category often results in a limited number of observations for particular product lines, and incomplete or missing data arising from gaps in the branding structure. We model these gaps ex-ante by constraining the Gibbs sampler in a particular way. Three, we argue that established brands and sub-brands in mature categories must be value-enhancing (or at the least be value-neutral) and that this translates into bounds on the domain of possible residual equity values. We propose the use of an asymmetric DP mixture base density to implement these ex-ante domain restrictions on the quantities of interest.

Most of the literature on equity measurements in Marketing has centered on the brand level - as brand equity and has tended to abstract away from explicitly modeling the effects of the entire branding structure, either by aggregating data to the brand level (e.g., Ailawadi et al., 2003) or analyzing a 'representative' SKU thereby ignoring the information present in the rest of the product portfolio in a category (e.g., Goldfarb et al., 2009). We incorporate information contained in the entire branding structure in a category in our estimation of ResEqty. Though there has been work on cross-category branding effects (e.g., Erdem, 1998 on umbrella branding), we confine the study to a within-category focus. Brand equity measurement schemes broadly fall into one of three classes (Ailawadi et al., 2003; Keller and Lehmann, 2006) - those based on primary data collected from consumers, those based on financial data of the firms, and those based on product-market outcomes.

Methods relying on primary data typically take a consumer-based perspective and seek to transform perception constructs such as attitude, awareness and liking for a brand into brand equity measures such as brand affects (Bousch et al., 1987) and brand-specific associations (Bhat and Reddy 2001). Costly and time-consuming individual level data is required to be collected through surveys or experiments. Further, these measures are based on stated preferences of respondents and consequently may not reflect real world (revealed preference) outcomes. In contrast, a notable advantage of our proposed method is that it relies on more accessible market level outcome data routinely collected by the firm or syndicated data providers, rather than primary data from individual consumers or households. 
The second class of brand equity measurement schemes uses firm level financial data to generate brand equity estimates based on measures such as acquisition prices (Mahajan, Rao and Srivastava 1994) and residual market values (Simon and Sullivan 1993). These brand equity estimates, however, are typically "firm equity" measures since the financial data used are at the firm level and most firms are multi-brand firms (Aaker and Jacobson 1994; Keller and Lehman, 2006). Hence, brand equity for a particular brand would be confounded with those of the firm's other brands. Combinations of data types and sources have also been utilized. For instance, Shankar, Azar and Fuller (2008) build a brand equity model that combines financial data with consumer survey data for multi-category brand in the insurance sector. In this paper, we demonstrate a financial brand valuation procedure that uses model results as input and does not require firm level measures such as stock price information.

The third class of measurement schemes adopts a product-market perspective and derives brand equity estimates from secondary data on market level outcomes. For instance, measures such as the additional willingness-to-pay for a branded product compared to an unbranded one (Aaker 1991, 1996; Sethuraman 2003), market-share and relative prices (Chaudhari and Holbrook 2001), segment-wise brand preferences (Kamakura and Russell 1993), revenue premiums (Ailawadi, Lehmann and Neslin 2003), and profit differentials (Dubin 1998; Goldfarb, Lu and Moorthy 2009) have been used to estimate brand equity. Our proposed approach falls within this class of methods.

We endeavor to demonstrate that given typical CPG branding structures, our proposed method bears advantages over alternative specifications. These advantages, apart from those mentioned previously, include equity estimation at each hierarchical level in the branding structure, easy and direct transformation of equity into a dollar metric, the incorporation of competition effects, and all this within a simple reduced form specification that makes relatively few assumptions on firm behavior.

The rest of this paper proceeds as follows. Section 2 develops a conceptual framework regarding the clean separation of marketing mix elements and non-unique product attributes from the unique ResEqty associations in the branding structure. Section 3 details an econometric model for ResEqty 
estimation. Section 4 describes the data. Sections 6 and 7 discuss the results and summarize any managerial insights therein.

\section{Conceptual Model}

We start with the following the general structure outlined in Aaker $(1991,2004)$ that is applicable across many CPG categories. Going from a high (supra-brand) to a low (SKU) level of product aggregation, we write:

\begin{tabular}{|c|c|}
\hline The Supra-Brand level & (For example, Pepsico) \\
\hline & \\
\hline \multirow[t]{2}{*}{ The Master Brand level } & (For example Pepsi) \\
\hline & $\square$ \\
\hline \multirow[t]{2}{*}{ The Sub-Brand level } & (For example, Diet Pepsi Cherry) \\
\hline & 25 \\
\hline The SKU level & (For example, Diet Pepsi Cherry 2 liter PET) \\
\hline
\end{tabular}

The figure above uses an example from the carbonated soft drinks category to illustrate the brand hierarchy. Additional levels can be incorporated as needed. To see the complexity inherent in the typical brand hierarchy, consider that each firm with a corporate brand name fields at least one master brand, each of which typically hosts at least one sub-brand and each sub-brand, in turn, hosts several SKUs. Whereas some master-brands may not have any sub-brands at all, others may have additional layers such as branded differentiators between sub-brands and SKUs. Suppose a firm wants to measure the sales bump attributable to a particular master brand (henceforth, simply 'brand'). Then it would first have to account for the sales influences of not just the marketing mix but also the SKU and sub-brand levels. More generally, the idea is to isolate the market response due to each hierarchical level in the branding structure. To do this, we propose the following model development path:

1. The observed market response is projected onto time-varying factors that influence product sales and onto the aggregated effect of the lowest level of product aggregation, namely, SKUs. 
2. These aggregate SKU effects are in turn projected onto (a) observed product attributes shared by other SKUs, (b) fixed effects for the next level of product aggregation, namely, sub-brands, and (c) systematic residual effects at the SKU level.

3. The sub-brand fixed effects are in turn projected onto (a) fixed effects for the next level of product aggregation, namely, brands, (b) onto observed sub-brand level product attributes, and (c) onto a residual equity term at the sub-brand level. This process continues until all product aggregation levels of interest are covered. We stop at the brand level in this application.

The 'time-varying factors' mentioned include marketing mix (henceforth, MMIX) elements such as price, promotion and distribution, competition effects, as well as category wide drivers of demand such as seasonality, potential market size, and inflation that change from one period (typically, a month or a quarter in the context of aggregate sales data available) to the next. Step 1 can be expressed as:

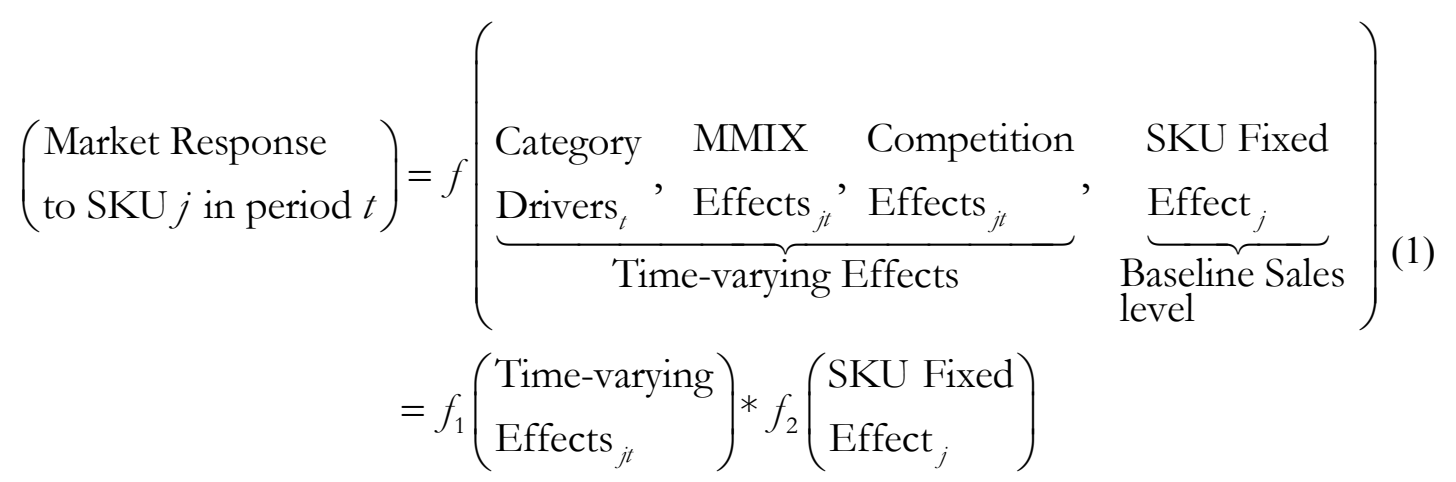

We make a case for the multiplicative formulation used in (1) and in other model equations later in this section. In equation (1), the 'SKU fixed effect' term represents a base-line level of the market response net of time-varying effects (e.g., Bronnenberg and Mahajan, 2001) and captures in aggregate the market response due to all time-invariant product attributes. These include the effect of (a) higher levels in the branding structure, (b) that of observed product attributes shared across SKUs (termed 'observed SKU level attributes'), and (c) that of any remaining systematic residual effects at the SKU level that are not recorded in the data. In (1), the SKU fixed effect for SKU $j$ appears as some function $f_{2}($.$) of the$ corresponding SKU dummy. Since (1) is multiplicative, following standard practice, we operationalize 
$f_{2}($.$) as an exponential function in order to facilitate downstream modeling in a log-log or constant$ elasticity framework. We address the mitigation of potential endogeneity biases in select MMIX variables in the next section. We assume that the aggregate effects of branding structure, shared attributes at and residual effects of each level in the branding structure are multiplicatively separable, thus:

$$
\begin{aligned}
f_{2}\left(\begin{array}{l}
\text { SKU Fixed } \\
\text { Effects }
\end{array}\right) & =g\left(\begin{array}{ll}
\text { Observed SKU } & \text { SKU Residual } \\
\text { Attributes } & \text { Sub-brand } \\
\text { Effects } & \text { Fixed Effects }
\end{array}\right) \\
& =g_{1}\left(\begin{array}{l}
\text { Observed SKU } \\
\text { Attributes }
\end{array}\right) * g_{2}\left(\begin{array}{l}
\text { SKU Residual } \\
\text { Effects }
\end{array}\right) * g_{3}\left(\begin{array}{l}
\text { Sub-brand } \\
\text { Fixed Effects }
\end{array}\right) .
\end{aligned}
$$

In (2), 'Observed SKU attributes' refers to product attributes such as size or packaging that are found also in other SKUs in the category and are not unique to any particular SKU. 'Sub-brand Fixed effects' captures the aggregate effect of all branding levels at and above the sub-brand level. Again, as with $f_{2}($.$) in (1), we choose g_{3}($.$) in (2) to be the exponent of the sub-brand dummy to facilitate$ downstream modeling (in a log-log expression). Lastly, 'SKU residual effects' represents the aggregate impact on market response due to all SKU level attributes, including unique branding structure associations, that are not recorded as variables in the data.

'Sub-brand Fixed effects' are further broken down under a multiplicative formulation, thus:

$$
g_{3}\left(\begin{array}{l}
\text { Sub-brand } \\
\text { Fixed } \\
\text { Effects }
\end{array}\right)=b_{1}\left(\begin{array}{l}
\text { Observed } \\
\text { Sub-brand } \\
\text { Attributes }
\end{array}\right) * h_{2}\left(\begin{array}{l}
\text { Sub-brand } \\
\text { Residual } \\
\text { Equity }
\end{array}\right) * b_{3}\left(\begin{array}{l}
\text { Brand level } \\
\text { Fixed } \\
\text { Effects }
\end{array}\right) .
$$

Similarly, 'Brand fixed effects' in (3) are broken down as:

$$
h_{3}\left(\begin{array}{l}
\text { Brand level } \\
\text { Fixed } \\
\text { Effects }
\end{array}\right)=r_{1}\left(\begin{array}{l}
\text { Observed } \\
\text { Brand } \\
\text { Attributes }
\end{array}\right) * r_{2}\left(\begin{array}{l}
\text { Brand } \\
\text { Residual } \\
\text { Equity }
\end{array}\right) .
$$


Equation (4) can be plugged into (3), (3) into (2), and (2) into (1) yielding:

$$
\begin{aligned}
\left(\begin{array}{l}
\text { Market } \\
\text { Response } \\
\text { to SKU } j \text { in } t
\end{array}\right)= & f_{1}\left(\begin{array}{l}
\text { Time } \\
\text {-varying } \\
\text { Factors }
\end{array}\right) * f_{2}\left(\begin{array}{l}
\text { Observed } \\
\text { SKU } \\
\text { Attributes }
\end{array}\right) * f_{3}\left(\begin{array}{l}
\text { Observed } \\
\text { Sub-brand } \\
\text { Attributes }
\end{array}\right) * f_{4}\left(\begin{array}{l}
\text { Observed } \\
\text { Brand } \\
\text { Attributes }
\end{array}\right) * f_{5}\left(\begin{array}{l}
\text { SKU } \\
\text { Residual } \\
\text { Effects }
\end{array}\right) \\
& * \underbrace{\left(\begin{array}{l}
\text { Sub-brand } \\
\text { Residual } \\
\text { Equity }
\end{array}\right) * f_{7}\left(\begin{array}{l}
\text { Brand } \\
\text { Residual } \\
\text { Equity }
\end{array}\right)}_{\text {Residual Equity Multiplier }(\text { REM })} .
\end{aligned}
$$

Equation (5) analyzes observed market response in terms of two distinct groups of variables in a multiplicative model - one, variables unrelated to branding structure, and two, a ResEqty multiplier that scales up the hypothetical market response due to a identical set of product attributes but devoid of branding structure associations. We simplify and express (5) as:

$$
\left(\begin{array}{l}
\text { Market Response } \\
\text { to SKU } j \text { in } t
\end{array}\right)=g_{0}\left(\begin{array}{l}
\text { Market Response } \\
\text { without branding } \\
\text { structure effects }
\end{array}\right) * g_{1}\left(\begin{array}{l}
\text { Residual } \\
\text { Equity } \\
\text { Multiplier }
\end{array}\right) .
$$

The advantages of a general multiplicative formulation are well-known. These include an easy transformation into linear form using logs, a natural diminishing-returns pattern implied by the logarithmic function, accommodation of various response shapes and rates (Lilien, Kotler and Moorthy, 1992) and an easy interpretation of coefficients as elasticities. In addition, the multiplicative functional form in (6), as applied particularly to brand effects, finds supporting evidence in both the experimental literature (e.g., Bousch et al., 1987) and the empirical literature (Sullivan, 1998). Bousch et al. find that brand associations raise/lower the perceived evaluation of other product characteristics. Sullivan (1998) analyzes the prices of 'twin automobiles' (manufactured in the same plant with the same set of features but selling under different brand names) using a multiplicative model and shows that twin automobiles command different prices in the used-car marketplace because of differences in perceived quality 
attributable to brand name. We assume the rationale for the multiplicative functional form extends to the sub-brand and the SKU levels.

A number of marketing outcomes such as sales units, revenue, or market share may be used as the market response metric. We choose revenue. A big reason is that revenue is the product of price and quantity, and both price and quantity are likely to be functions of MMIX as well as brand equity. Thus, by modeling revenue as the dependent variable, placed on the LHS of the model equation in (1), we circumvent the need to have either price or quantity in the RHS, greatly simplifying the analysis. In addition, revenue is recorded in scanner data at every level of product aggregation; has previously been used as a brand equity metric (e.g., Ailawadi, Lehmann and Neslin 2003); and the economic rationale behind the restrictions in our model applies readily to revenue.

We now introduce economic restrictions on the behavior of the Sub-brand Residual Equity (henceforth, ResEqty ${ }^{(S B)}$ ) in (3) and the Brand Residual Equity (henceforth, ResEqty ${ }^{(B R D)}$ ) term in (4). ResEqty $^{(B R D)}$ aggregates the systematic revenue response due to all brand level influences and manifests as a multiplier for the average revenue of an identical, unbranded attribute bundle. We argue that at least in mature categories, for brands that have survived in the market for a few years, brands must be valueenhancing. That is, a brand must provide added value to a product or its producer would not utilize the brand name and would rather sell the unbranded, equivalent product. In other words, given our multiplier formulation, the ResEqty ${ }^{(B R D)}$ multiplier must be greater than or equal to one. If a particular brand's ResEqty $^{(B R D)}$ were less than one, then its unbranded equivalent would earn more revenue than it does. Since the only difference is the brand name, it must be that the brand name actively destroys product value. Since building and deploying a brand incurs positive costs, a $\operatorname{ResEqty}^{(B R D)}<1$ implies the firm would be strictly better off withdrawing the brand name from the product. $^{3}$ In sum, the

\footnotetext{
${ }^{3}$ With new brands it is possible that not yet enough market data are available to weed out underperforming brands or sub-brands (with sub-brand $\mathrm{RE}<1$ or Brand $\mathrm{RE}<1$ ). However, this is unlikely to be the case with long-standing
} 
ResEqty $^{(B R D)}$ measure for each brand is modeled as an asymmetric effect constrained to lie on $[1, \infty)$ due to the firm's rational, profit maximizing behavior.

A similar rationale applies also at the sub-brand level. A sub-brand is added to a given set of product characteristics because it enhances product sales. At the very least, addition of the sub-brand would not detract from product sales because otherwise, firms would be strictly better off withdrawing the sub-brand from that product. Thus, the sub-brand equity or ResEqty ${ }^{(S B)} \geq 1$.

We do not, however, extend the domain restriction argument to SKUs for two reasons. One, in CPG categories, SKUs are introduced and withdrawn at a relatively fast clip. Even minor changes in packaging and labeling, regulations about which may vary by state, would lead to the creation of new SKUs in the data. Thus, the concept of an 'established' SKU in the sense that a brand or sub-brand over some years is established may not be straight forward to operationalize.

Two, since SKUs are the vehicle that deploys the actual, physical CPG product into the marketplace, it is the SKU level that is most likely to carry the largest share of objective and physical attributes that are not protected against imitation by copyright. In contrast, elements of brand and subbrand identity are protected by copyright and constitute the visible means by which the promise, assurance, familiarity and other experience attributes are conveyed. Thus, brands and sub-brands are likely to represent the bulk of the unique branding associations we seek to measure using ResEqty. We make the assumption that the net effect ${ }^{4}$ of latent, non-unique attributes for brands and sub-brands, unlike for SKUs, is small relative to the unique branding association effects in their ResEqty terms and does not significantly bias the results. Hence, we do not posit any (SKU Residual Effect) $\geq 1$ condition, and we use the term residual effects rather than residual equity for SKUs.

brands in a mature category such as beer. Furthermore, grocery brand withdrawals are numerous (Haig, 2005), which suggests that firms withdraw failed brands and products fairly quickly.

${ }^{4}$ Not all the product attributes observed by consumers can be present in the data, and so these omitted attributes show up in the residual effects at different branding levels. Some of these latent attributes may have positive impact on market response, others may have a negative impact. The net impact of latent, non-unique attributes may confound the unique branding structure associations that we are interested in measuring. 
In seeking to obtain reasonably accurate estimates of ResEqty ${ }^{(B R D)}$, ResEqty ${ }^{(S B)}$ and ResEffect $^{(S K U)}$ (to henceforth denote SKU residual effects) we propose to relate factors in the RHS of (1) to sales revenue using a general multiplicative formulation for the reasons mentioned in the previous section. We factorize revenue into a set of distinct factors corresponding to broad determinants of product demand and to capture the impact of these revenue factors using variables observed in the data. Let $j$ denote SKU, $t$ denote time-period, $b$ brand, and $v$ sub-brand. Then the model in (1) can now be more explicitly expressed as:

$$
\begin{aligned}
\text { Revenue }_{j t}= & e^{\beta_{0}} \prod_{a=1}^{A}\left(\begin{array}{l}
\text { Category }_{\text {Drivers }_{a, t}}
\end{array}\right)^{\beta_{a}} * \prod_{c=A+1}^{C}\left(\begin{array}{l}
\text { Promotion }_{\text {Mix Elements }_{c, j t}}
\end{array}\right)^{\beta_{c}} * \prod_{d=C+1}^{D}\left(\begin{array}{l}
\text { Distribution }_{\text {Measures }_{d, j t}}
\end{array}\right)^{\beta_{d}} \\
& * \prod_{l=D+1}^{L}\left(\begin{array}{l}
\text { Competition }_{\text {Measures }_{l, j t}}^{\beta_{l}}
\end{array}\right)^{*} * \exp \left(\delta_{j} * \operatorname{SKU}_{j} \text { Dummy }_{j}\right) * e^{\varepsilon_{j t}}
\end{aligned}
$$

Here, $\varepsilon_{j(b) t}$ is an IID noise term interpreted as measurement error, and the corresponding SKU fixed effect measures the systematic revenue impact of SKU $j$. To facilitate econometric implementation, take logs on both sides of (7), obtaining:

$$
\begin{aligned}
& \text { LnRevenue }_{j t}=\beta_{0}+\sum_{a=1}^{A} \beta_{a} * \operatorname{Ln}\left(\begin{array}{l}
\text { Category } \\
\text { Drivers }_{a, t}
\end{array}\right)+\sum_{c=A+1}^{C} \beta_{c} * \operatorname{Ln}\left(\begin{array}{l}
\text { Promotion } \\
\text { Mix Elements }_{c, j t}
\end{array}\right) \\
&+\sum_{d=C+1}^{D} \beta_{d} * \operatorname{Ln}\left(\begin{array}{l}
\text { Distribution } \\
\text { Measures }_{d, j t}
\end{array}\right)+\sum_{l=D+1}^{L} \beta_{l} * \operatorname{Ln}\left(\begin{array}{l}
\text { Competition } \\
\text { Measures }_{l, j t}
\end{array}\right) \\
&+\left(\begin{array}{l}
\text { SKU Fixed }_{\text {Effect }_{j}}\left(\delta_{j}\right)
\end{array}\right)+\varepsilon_{j t}, \\
& \varepsilon_{j(b) t} \sim \operatorname{IID} f\left(0, \sigma_{\varepsilon}^{2}\right) .
\end{aligned}
$$

For simplicity, we re-write (8) as:

$$
\begin{aligned}
& \operatorname{Ln}\left(Y_{j t}\right)=\beta_{0}+\mathbf{X}_{j t} \beta_{1}+\mathrm{FE}_{j}^{(S K U)}+\varepsilon_{j t}, \\
& \varepsilon_{j t} \sim \operatorname{IID} f\left(0, \sigma_{\varepsilon}^{2}\right) .
\end{aligned}
$$


Here, $Y_{j t}$ denotes sales revenue for SKU $j$ in period $t, \mathbf{X}_{j t}$ the $\log$ of the set of time-varying factors that impact $\operatorname{Ln}\left(Y_{j t}\right), \beta$ the corresponding parameter vector, and the fixed effect for $j$, denoted by $\mathrm{FE}_{j}^{(S K U)}$, represents the SKU fixed effect.

We know that the MMIX levels for a branded product are set by managers who are aware of the brand equity of the product and of rival products, and hence, are likely to be endogenous. We address potential endogeneity in suspect MMIX variables using a set of exogenous or pre-determined instruments matrix $\mathbf{H}$ in a classic 2SLS-IV estimator setup. The projections of MMIX on $H$ would be free of endogeneity bias and we use these corrected values in subsequent analysis. The details of the procedure are described in the data section.

The log of aggregate SKU effects $\mathrm{FE}_{j}^{(S K U)}$ in (9) is modeled as:

$$
\begin{aligned}
& F E_{j}^{(S K U)}=\delta_{0}+\mathbf{X}_{j}^{(S K U)} \boldsymbol{\delta}_{1}+F E_{v(j)}^{(S B)}+\xi_{j}^{(S K U)}+\varepsilon_{j}^{(\mathrm{SKU})}, \\
& \varepsilon_{j}^{(\mathrm{SKU})} \sim \operatorname{IID} N\left(0, \sigma_{\varepsilon}^{2} \varepsilon^{S K U}\right) .
\end{aligned}
$$

Here, $\mathbf{X}_{j}^{(S K U)}$ is the log of the set of shared SKU level product attributes for $j$. The log of aggregate subbrand level effects for sub-brand $v$ corresponding to $\mathrm{SKU} j$ is modeled as $F E_{v(j)}^{(S B)}$ for sub-brand fixed effects, and captures the aggregate outcome contribution due to all branding levels higher than the SKU level. When the contribution of $\mathbf{X}_{j}^{(S K U)}$ and $F E_{v(j)}^{(S B)}$ is accounted for and removed, what remains is the residual effect at the SKU level, which we term $\xi_{j}^{(S K U)}$.

In (10), $\xi_{j}^{(S K U)}$ cannot be estimated by fixed effects as the number of observations equals the number of $\xi_{j}^{(S K U)}$ terms. One alternative is a random effects specification using a parametric functional form. Unfortunately, while relatively easy to model and estimate, the choice of any parametric density would be quite arbitrary and it may happen that the model does not fit the data at hand very well. This is particularly so if the data are multimodal, skewed, having outliers or are otherwise heterogeneous. 
Further, it may be that the $\xi_{j}^{(S K U)}$ values for different $j$ all do not even come from the same distribution. Based on these observations, it is desirable to take the distribution of $\xi_{j}^{(S K U)}$ from a sufficiently large class to capture such possibilities. We later extend the same arguments to the log of ResEqty terms for subbrand and brand, namely, $\xi_{v}^{(S B)}$ and $\xi_{b}^{(B R D)}$.

A second approach would be to use a finite mixture of continuous densities (see, e.g., Allenby, Arora and Ginter, 1998), which generalizes and extends the latest class method (Kamakura and Russell, 1989) in that it is able to model within-segment heterogeneity. Although finite mixtures of component densities are able to adequately recover complex heterogeneity distributions, the 'correct' number of mixing components is not known a priori, and determining it requires tedious and often difficult test procedures (Andrews and Currim, 2001). Further, the issues of label switching (e.g., Celeux et al., 2000) and overlapping mixtures (Roeder, 1994) are yet to be satisfactorily resolved in many applications (Kim, Menzefricke and Feinberg, 2004). To retain generality, a large number of mixture components is preferred at the outset. Paradoxically, rather than handling the very large number of parameters resulting from finite-mixture models with a large number of mixture components, it may be easier to work with an infinite-dimensional specification by assuming a random mixing distribution that is not restricted to a specified parametric family and that also avoids identification issues. In this vein, motivated by the work of Ishwaran and Zarepour (2002), we place a nonparametric Bayesian prior on $\xi_{v}^{(S B)}$ and $\xi_{b}^{(B R D)}$ that can capture heterogeneity in a flexible yet structured manner.

The Dirichlet Process Mixture Model

Motivated by the discussion in the preceding paragraphs, we propose a Dirichlet Process Mixture (henceforth, DPM) model (Antoniak, 1974; Ferguson, 1973, 1983) to estimate $\xi_{j}^{(S K U)}$ thus: 


$$
\begin{aligned}
& \xi_{j}^{(S K U)} \mid G_{1} \sim G_{1}, \\
& G_{1} \mid \alpha_{01}, G_{01} \sim D P\left(\alpha_{01}, G_{01}\right), \\
& G_{01} \mid \sigma_{S K U}^{2} \sim N\left(0, \sigma_{S K U}^{2}\right), \\
& \alpha_{01} \sim \text { Uniform }(0.3,10) .
\end{aligned}
$$

Here, $G_{1}$ is a random probability distribution that is not observed and is drawn from a Dirichlet process $\operatorname{DP}\left(\alpha_{01}, G_{01}\right)$ with concentration parameter $\alpha_{01}$ and base distribution $G_{01}$. We use a uniform prior on $\alpha_{01}$ following Ohlssen et al. (2007) ${ }^{5}$ and use a normal base distribution with location parameter normalized to zero and variance $\sigma_{S K U}^{2}$. For brevity, we condense (11) and write $\xi_{j}^{(S K U)} \sim \operatorname{DP}\left(\alpha_{01}, G_{01}\right)$.

Other levels in the branding structure are analyzed following (10). Thus, the $F E_{v(j)}^{(S B)}$ term in (10) is broken down into its constituent parts, thus:

$$
\begin{aligned}
& F E_{v}^{(S B)}=\gamma_{0}+\mathbf{X}_{v}^{S B} \gamma+F E_{b(v)}^{(B R D)}+\xi_{v}^{(S B)}+\varepsilon_{v}^{(S B)}, \\
& \xi_{v}^{(S B)} \sim \operatorname{DP}\left(\alpha_{02}, G_{02}\right), \\
& \varepsilon_{v}^{(\mathrm{SB})} \sim \operatorname{IID} N\left(0, \sigma_{\varepsilon^{S B}}^{2}\right) .
\end{aligned}
$$

Here, $\mathbf{X}_{v}^{S B}$ denotes a log transformation (as appropriate) of shared product attributes at the sub-brand level $v, \gamma$ the corresponding parameter vector, $F E_{b(v)}^{(B R D)}$ the fixed effect of brand $b$ corresponding to $v$, and $\xi_{v}^{(S B)}$, the log of ResEqty ${ }^{(S B)} \cdot \xi_{v}^{(S B)}$ is assumed distributed following a DP. $F E_{b(v)}^{(B R D)}$, following (10) and (12), is broken down further, as:

$$
\begin{aligned}
& F E_{b}^{(B R D)}=\theta_{0}+\mathbf{X}_{b}^{(B R D)} \boldsymbol{\theta}+\rho_{b}^{(B R D)}+\varepsilon_{b}^{(B R D)}, \\
& \rho_{b}^{(B R D)} \sim \operatorname{DP}\left(\alpha_{03}, G_{03}\right), \\
& \varepsilon_{b}^{(B R D)} \sim \operatorname{IID} N\left(0, \sigma_{\varepsilon^{B R D}}^{2}\right) .
\end{aligned}
$$

\footnotetext{
${ }^{5}$ Two advantages accrue from using the uniform prior - one, it is non-informative and hence allows data the most say in determining the value of $\alpha$, and two, potential computational traps in BUGS software are avoided by having 0.3 as the lower bound (Spiegelhalter et al., 2003)
} 
Again, in (13), $\mathbf{X}_{b}^{(B R D)}$ represents shared product attributes at the brand level, $\boldsymbol{\theta}$ the corresponding parameter vector, and $\xi_{b}^{(B R D)}$ the log of the ResEqty at the brand level assumed distributed according to a DP.

The economic restrictions proposed, namely that $\operatorname{ResEqty}^{(S B)} \geq 1$ and $\operatorname{ResEqty}^{(B R D)} \geq 1$, translate into non-negativity constraints, as $\xi_{v}^{(S B)} \geq 0$ and $\xi_{b}^{(B R D)} \geq 0$ respectively. To incorporate these economic constraints, ex-ante, into the DP model, we propose asymmetric base distributions for the DP terms in (12) and (13) thus:

$$
\begin{aligned}
& G_{02} \mid \sigma_{S B}^{2} \sim N^{+}\left(0, \sigma_{S B}^{2}\right), \\
& G_{03} \mid \sigma_{B r d}^{2} \sim N^{+}\left(0, \sigma_{B r d}^{2}\right) .
\end{aligned}
$$

Here, $N^{+}\left(0, \sigma^{2}\right)$ denotes a half-normal density with variance $\sigma^{2}$. Similar to $\alpha_{01}$, both $\alpha_{02}$ and $\alpha_{03}$ are distributed with a non-informative uniform $(0.3,10)$ prior. Equations $(10),(12)$ and (13) can be combined and plugged into (9), thus:

$$
\begin{gathered}
\operatorname{Ln}\left(Y_{j t}\right)=\left(\beta_{0}+\delta_{0}+\gamma_{0}+\theta_{0}\right)+\left(\mathbf{X}_{j t} \boldsymbol{\beta}+\mathbf{X}_{j}^{(S K U)} \boldsymbol{\delta}+\mathbf{X}_{v}^{(S B)} \boldsymbol{\gamma}+\mathbf{X}_{b}^{(B R D)} \boldsymbol{\theta}\right) \\
+\left(\xi_{j}^{(S K U)}+\xi_{v}^{(S B)}+\xi_{b}^{(B R D)}\right)+\left(\varepsilon_{j t}+\varepsilon_{j}^{(S K U)}+\varepsilon_{v}^{(S B)}+\varepsilon_{b}^{(B R D)}\right) .
\end{gathered}
$$

In (15), the various intercept terms can be rolled into one as $\mu_{0}=\left(\beta_{0}+\delta_{0}+\gamma_{0}+\theta_{0}\right)$, the IID $\varepsilon$ error terms can be rolled into one term as $e_{j t}=\left(\varepsilon_{j t}+\varepsilon_{j}^{(\mathrm{SKU})}+\varepsilon_{v}^{(\mathrm{SB})}+\varepsilon_{b}^{(\mathrm{Brd})}\right)$, with $e_{j t}$ distributed IID normal with some variance $\sigma_{e}^{2}$, and each of $\xi_{j}^{(S K U)}, \xi_{v}^{(S B)}$ and $\xi_{b}^{(B R D)}$ are assumed distributed according to an independent DP with separate parameters. Thus, we write: 


$$
\begin{aligned}
& \operatorname{Ln}\left(Y_{j t} \mid \mu_{0}, \mu, \text { DATA },\{\xi\}\right)=\mu_{0}+\text { DATA }_{j t} \mu+\left(\xi_{j}^{(S K U)}+\xi_{v}^{(S B)}+\xi_{b}^{(B R D)}\right)+e_{j t}, \\
& \xi_{j}^{(S K U)} \sim D P\left(\alpha_{01}, G_{01}\right), \\
& \xi_{v}^{(S B)} \sim D P\left(\alpha_{02}, G_{02}\right), \\
& \xi_{v}^{(B R D)} \sim D P\left(\alpha_{03}, G_{03}\right), \\
& e_{j t} \sim N\left(0, \sigma_{e}^{2}\right) .
\end{aligned}
$$

Although the development of the conceptual model was laid out using multiple steps, we reiterate that the final model in (16) is estimated jointly, in a single step, using Markov Chain Monte Carlo (MCMC) methods. The Gibbs sampler for the MCMC routine is easy to implement and is coded in OpenBUGS software.

We illustrate the handling of gaps in the branding structure in the following way - suppose a brand has no sub-brand. Then, the $\xi_{v}^{(S B)}$ value corresponding to the non-existent sub-brand is fixed to zero, ex-ante, outside the MCMC routine. This value is not subsequently updated and the Gibbs sampler does not use it in any way when estimating the $\xi_{v}^{(S B)}$ for other products. We do likewise for sub-brands that have only one SKU in the sample.

Following (6), a dollar metric is easily derived. The Residual Equity Multiplier (REM) for SKU j' in period $t$ is simply $\xi_{v}^{(S B)} * \xi_{b}^{(B R D)}$. So the hypothetical revenue of an unbranded bundle of $j$ 's attributes in $t$ would simply be Revenue ${ }_{j t}$ divided by the REM. And so, the dollar premium in revenue earned aggregated to the brand level becomes:

$$
\left(\begin{array}{l}
\text { Revenue Dollar }_{\text {Premium }_{b}}^{T}
\end{array}\right)=\sum_{t=1}^{T} \sum_{j \in v(b)} \text { Revenue }_{j t} *\left(1-\frac{1}{\xi_{v}^{(S B)} * \xi_{b}^{(B R D)}}\right) .
$$

Since a brand's revenue dollar premium effectively monetizes it's unique branding associations, it becomes a natural input to any branding structure valuation exercise ${ }^{6}$. We next describe the data used to implement (16).

\footnotetext{
${ }^{6}$ If we interpret the revenue due to the unbranded equivalent set of products as the quantity times the average variable cost of producing the branded products, then revenue dollar premium represents the net return or profit due
} 


\section{$4 \quad$ Data}

Beer data collected from a variety of readily available sources are used to illustrate the methodology. The U.S. beer market is a well defined and mature product category with characteristically little change in the total quantity of beer sold during the sample period 2002 - 2005. As with sales, distribution, promotion and price levels differ widely across brands, sub-brands and SKUs. Distribution is a major determinant of sales, and promotions - especially advertising (\$1.175 billion in 2005) and retail merchandising (features, displays, and temporary price reductions) are utilized heavily. However, while the category is dominated by a handful of big brands and manufacturers with extensive distribution and large promotional programs (Anheuser-Busch, SAB Miller, Molson-Coors and Pabst account for over $81 \%$ of U.S. sales), smaller, more regionally distributed brands compete quite effectively. Indeed, the collective share of the top 25 beer brands we analyze is slowly falling. We note also that even these major brands have numerous SKUs that receive limited distribution and promotion.

We detail a variety of measures constructed using fields in UPC scanner data to reflect the impact of the determinants of revenue outlined in equation (8). Table 1 summarizes these data fields and uses subscripts to denote the level at which each measure applies. Table 2 briefly profiles the 25 top selling beer brands.

\section{Revenue}

For the revenue measure, Revenue, we use monthly AC Nielsen national revenue data pertaining to the various SKUs that constitute the top 25 beer brands sold in food stores for the years 2002 to $2005 .^{7}$ We define "brand" as the identifier for any group of products which share a nominal label, "sub-brand" as a subset of the brand that differs from other sub-brands within the same master brand by some identifier or descriptor in the label, and "SKU" as any packaging or size of the product that differs from other

to branding structure for a brand. We use this interpretation of the revenue dollar premium in this paper detail a brand valuation procedure based on a simple discounted cash flow framework.

${ }^{7}$ Each 4-week period is referred to as a month. The beer category is defined as lagers and light beers since they constitute the vast majority of all malt beverages sold (i.e., malt liquors, stouts, ales and flavored malt beverages are not included in the analysis). 
products of the same sub-brand. For example, Budweiser is a brand, Bud Light and Bud Ice are two subbrands of Budweiser, and a six pack of 12 ounce Bud Light longneck bottles is a different SKU from a six pack of Bud Light 12 ounce cans.

In order to keep the number of SKUs analyzed to a reasonable level, we removed SKUs that were not sold over at least half the sample time span, had sales totaling less than $\$ 10$ million over the four year period or had a distributional reach of less than $10 \% \mathrm{ACV}^{8}$ (i.e., was accessible to less than $10 \%$ of purchasing power, nationwide). Consequently, the dataset contains 13,777 observations pertaining to 278 SKUs which constitute 25 brands. These SKUs account for over $90 \%$ of category revenue in U.S. food stores. In turn, food stores as defined by AC Nielsen account for about $88 \%$ of total beer sales at all food, drug and mass merchant outlets.

\section{Product}

Beverage Industry trade publications (e.g., Adams Beer Handbook) and item descriptors in AC Nielsen scanner data provide easily observed objective attributes that differentiate products by beer type, beer color, packaging and country of origin. Among SKU level attributes, the dummy variable Can tells if the beer container is a can as opposed to a bottle, dummies SinglePk, Sixpk, Twelvepk and Case refer to one beer container per sale unit, 6 packs of beer per sale unit, 12 packs and 18packs or higher respectively. The reference packaging type NonstdPk refers to non-standard pack sizes of 4,8,10 or 20 packs per sale unit. $\mathbf{O z}$ gives the total volume of beer in fluid ounces in a sale unit, and its quadratic term $\mathbf{O z}^{2}$ is also used to better measure the shape of response to SKU size. Among sub-brand level attributes, four dummy variables identify whether a particular sub-brand is of the Dry, Lite, Ice or Craft beer type rather than the reference type Regular. Three dummies identify whether a SKU's color is Amber, Light, or Golden rather than Dark. ABV for '\%Alcohol by Volume', and its square $\mathbf{A B V}^{2}$ are also used. Lastly,

\footnotetext{
${ }^{8}$ The AC Nielsen measure ACV, or All Commodity Volume, is the revenue-weighted \% of grocery stores that sold at least one unit of the product. It proxies for the demand to which the product is exposed to.
} 
a supra-brand characteristic, namely, the dummy Imported, for beers originating outside the U.S. is also used.

\section{Distribution \& Promotion}

Two standard scanner data measures - \%ACV Distribution and \%ACV Merchandizing -give the percentage of stores, weighted by store revenue, which sell at least one unit of a particular SKU in a given time period, and in which the SKU underwent some form of retail merchandising (displays, features and temporary price reductions) during each month, respectively. The observed levels of these variables are likely to be endogenous and hence are corrected for using a classic 2SLS-IV estimator as mentioned in the model section. In particular, we project each suspect MMIX variable $l$ onto a corresponding set $\mathbf{H}_{l}$ of exogenous or pre-determined variables and, following a 2SLS framework, use only the projections in the RHS of (9). Thus, for the $l^{\text {th }}$ MMIX variable in the dataset, MMIX

$$
\hat{\mathbf{M M I X}} \mathbf{X}_{l}=\mathbf{H}_{l}\left(\mathbf{H}_{l}^{T} \mathbf{H}_{l}\right) \mathbf{H}_{l}^{T} \mathbf{M M I X}_{l}, l=1,2, \ldots L .
$$

Here, $\mathbf{H}_{l}$ is the instrument matrix for $\mathbf{M M I X}$ and $\hat{\mathbf{M M I X}}$ is its endogeneity corrected value. The $\mathbf{H}$ matrices consist of exogenous or pre-determined variables such as product attributes, time dummies, price instruments such as purchasers' price indices and food inflation indices from the Bureau of Labor Statistics (BLS) and a one-period lagged MMIX variable. \%ACVMerchandizing ${ }^{\wedge}$ and \%ACVDistribution` are the corresponding 'clean' or endogeneity-corrected MMIX levels respectively for each item in each period.

From the Leading National Advertisers database, we acquired the annual advertising expenditure (AdSpend) of each sub-brand in each year studied. To measure shelf presence, a key determinant of sales (Little 1979; Guadagni and Little, 1983; Hoch et al., 1995), we construct a variable termed SKUnum from standard scanner data, as the average number of distinct SKUs in each sub-brand. Higher the SKUnum, typically, the more the shelf space.

\section{Competition}


Whereas in a Logit model, purchase probability or market share relate to the MMIX of all the products in the sample and thereby implicitly account for competition effects, this is not so in ordinary linear regressions. To build a simple and parsimonious measure of inter-SKU competition, we take interproduct distance between product 'locations' in time-attribute space as a measure of consumer preference similarity (Carpenter and Nakamoto, 1989) and hence, of inter-product substitutability. We add a time dimension to the attribute space and model the competition level affecting the sales of item $j$ in time $t$ due to all the other rival products in the market at time $t$ as:

$$
\text { Competition }(j t, .)=\sum_{\substack{i=1 \\
i \neq j}}^{J}\left\{\begin{array}{r}
{\left[\frac{1}{A} \sum_{a=1}^{A} I\left(i t \in D_{a}(j t)\right)\right] *\left(\begin{array}{l}
\text { Availaility of } \\
\text { rival item } i \text { in period } t
\end{array}\right)} \\
*\left(\begin{array}{l}
\text { Promotion intensity of } \\
\text { rival item } i \text { in period } t
\end{array}\right)
\end{array}\right\} .
$$

Here, for the set of observable binary attributes $a=1,2, \ldots A$ along which products compete, $D_{a}(j t)$ is the set of SKUs (excluding $j$ ) that share attribute $a$ with $j$ during period $t$, and $I($.$) is an indicator$ function. We find that this competition measure yields realistic cross-substitution patterns.

\section{Category Drivers}

Various economic and demographic factors are likely to impact industry-wide revenues (and hence, the sales of the particular SKUs). The monthly number people in the U.S. over age 21 (AdultPop), obtained from the U.S. Census Bureau, provides a nice proxy for changes in total market size. Input prices are likely to impact retail prices and, hence, revenues. So, from the Bureau of Labor Statistics database, the producer price index for long haul trucking in the U.S. (FreightPPI) serves as an input cost measure. Since imported beer prices are affected by foreign exchange rates (ExchgRate), a monthly averaged index of the Canadian Dollar, Mexican Peso and Euro exchange rates per U.S. dollar (obtained from the Federal Reserve website) acts as an additional cost measure for the imported brands. Seasonality also is prevalent in this industry, so three simple quarterly dummies (Fall, Winter and Spring) are 
utilized. To proxy for additional unobserved factors that that may influence market level demand, three yearly time dummies (Year2002, Year2003 and Year2004) are also instituted.

\section{$6 \quad$ Results and Discussion}

Two broad classes of results emerge from the estimation of the model in (16) - the main effects and the residual effects. Of the residual effects, we have ResEqty ${ }^{(S B)}$ and ResEqty ${ }^{(B R D)}$ at the individual

brand and sub-brand levels respectively and ResEffect ${ }^{(S K U)}$ pertaining to the SKU. The main and residual effects are presented in order and their face validity is assessed. Subsequently, the ResEqty results feed into a brand valuation exercise that will aid in externally validating the model.

\subsection{Discussion of Main Effects}

Table 3 shows the main effects for equation (16). Credibly nonzero estimates (those for which the $95 \%$ credibility interval excludes zero) are marked in bold font.

Among the product attributes at the sub-brand level, we find that Lite beers are preferred over other beer types, and that Light and Golden colored beers sell better than the other colors. Domestic beers sell better than Imported ones after controlling for other attributes. The coefficient of ABV (\%Alchohol by Volume) is positive whereas that $\mathbf{A B V}^{2}$ is negative indicating a concave revenue response to \%alcohol levels in beer. Hence, at both the low and the high end of \%alcohol levels, beers don't sell as well as they seem to do in some optimal ABV range in the middle. This is intuitive. Similarly, the coefficient of SKU size on fluid ounces, $\mathbf{O z}$ is positive while its quadratic term $\mathbf{O z}^{2}$ is negative indicating that there is an optimum beer volume per sale unit and SKUs near this optimum sell better than those above and below it. Among packaging attributes at the SKU level, Can is positive suggesting that beer in cans sells better than in bottles, and beer six-packs appear to outsell single packs, 12 packs and cases, after controlling for other factors.. The time-varying MMIX effects in both distribution and promotion measures in the revenue regression are also along expected lines. We find that Distributional reach, 
promotional activity ${ }^{9}$, shelf space and advertising spend all positively relate to revenue. In terms of magnitude, distributional reach has the highest impact, followed by promotional activity, advertising spend and finally, shelf space. The elasticity of distribution is 0.96 suggesting that a $1 \%$ rise in distribution achieves close to a $1 \%$ rise in sales revenue for any SKU.

The Category Drivers show intuitive appeal and are credibly nonzero. The time dummies decrease from year to year, reflecting the slight downward trend in the revenue total of the top 25 beer brands. As for the seasonal dummies, beer consumption, unsurprisingly, rises along with outdoor temperatures. The size of the U.S. adult population, a proxy for market size, also positively impacts sales revenue. The exchange rate parameter is also positive indicating that the cheaper imports are in U.S. dollars, the higher is their sales revenue. This is consistent with an absolute price elasticity greater than one in the beer category ${ }^{10}$. Also consistent with this finding, increases in the cost of long haul freight raise prices and lower revenue.

Overall, the main effects results appear intuitive in sign, reasonable in magnitude, are overall credibly nonzero, and thereby lend face validity to the results.

\subsection{Discussion of Residual Equity}

We now investigate the residual effect of branding structure on revenue. The model output yields precise unit-level estimates ${ }^{11}$ of the SKU specific residual and its logarithm, $\xi^{(S K U)}$, for each SKU, the sub-brand specific ResEqty and its $\log , \xi^{(S B)}$, for each of sub-brand and the brand specific RE and its $\log$, $\xi^{(B R D)}$, for each brand in the sample. The 'gaps' or missing levels in the branding structure are visible in that there are 6 sub-brands with just one SKU, and 19 brands with no sub-brand distinct from the master

\footnotetext{
${ }^{9}$ The 2SLS estimation for the endogeneity corrected MMIX variables \%ACVMerchandizing $\wedge$ and \%ACVDistribution^ yields a high adjusted R-square of over 0.90 .

${ }^{10}$ A regression of the log of beer volume sold against the observed MMIX variables and price per unit volume over the sample data results in a price elasticity estimate of approximately -2.66 .

${ }^{11}$ These residual effects estimates are obtained as draws from their respective marginal posterior densities. We use a burn-in of 200,000 iterations to give the sampler ample time to converge to the true joint posterior and sample every tenth draw to mitigate any potential autocorrelation effects. Further, following Spiegelhalter and Ghosh (2002), our use of a lower bound of at least $\sqrt{n}$ mixture components (where $n=$ number of units) appears to cover sufficient number of clusters.
} 
brand. Thus, we estimate log residual effects for 272 SKUs setting the other 6 to 0 , and for 37 sub-brands setting the other 19 to 0 .

First, we inquire into estimate significance. We find that of 272 SKU specific residuals, 256 are credibly nonzero, that is, their $95 \%$ credibility intervals do not include 1 . Similarly, 20 of the 37 subbrands and 20 of the 25 brands have credible ResEqtys in that their 95\% credible interval excludes 1 . Thus, the results clearly show that a systematic residual effect of the branding structure on market response exists and is credibly nonzero in the clear majority of the products sampled.

Second, we ask if the additional flexibility and the ability to recover complex heterogeneity patterns implied by DPM model mattered in this application and pre-view what the results say about the quality of the estimates. Figure 1 displays the histograms of the means of the SKU specific residual, the $\operatorname{ResEqty}^{(S B)}$ and the ResEqty ${ }^{(B R D)}$ estimates and that of their respective logs. Whereas the base distributions of the DP mixtures for $\xi^{(B R D)}$ and $\xi^{(S B)}$ were both half-normal (from equation (14)), the output distributions of $\xi^{(B R D)}$ and $\xi^{(S B)}$ aren't necessarily half-normal. Whereas the histogram of $\xi^{(B R D)}$ in panel (a) of Figure 1 resembles a half-normal shape, that of $\xi^{(S B)}$ in panel (c) certainly does not. Applying standard parametric functional forms to approximate such shapes would force the final distribution of $\xi^{(B R D)}$ and $\xi^{(S B)}$ along a particular pre-determined shape and therefore, may yield misleading results ${ }^{12}$. Further, we know that Bayesian estimation yields the exact finite sample marginal posterior densities for the ResEqtys of each brand and sub-brand and the ResEffect ${ }^{(S K U)}$ for each SKU in the sample. Figures 2 and 3 depict the non-parametric density plots of the ResEqtys for 16 major brands and sub-brands respectively. The solid vertical line marks the mean ResEqty. The plots clearly indicate that the posterior density shapes for ResEqty ${ }^{(S B)}$ and ResEqty ${ }^{(B R D)}$ estimates are complex in shape, vary considerably in

\footnotetext{
${ }^{12}$ We test this by implementing a stochastic frontier model of residual equity with ResEqty ${ }^{(B R D)}$ and ResEqty ${ }^{(S B)}$ assumed distributed independently half-normal. We find that whereas ResEqty ${ }^{(B R D)}$ results are comparable with those obtained from our DP specification, those of ResEqty ${ }^{(S B)}$ show marked differences. These results are not presented for lack of space but are available from the authors on request.
} 
value and have relatively small variance for the vast majority of brands and sub-brands. Again, skew and multi-modality are clearly seen. In particular, the low variance of the marginal densities implies good approximation of the target ResEqty quantity with a point estimate such as the mean of the density.

Third, we ask how the ResEqty is distributed across the branding structure and what the implications are therein. The ResEqty figures across branding levels are not directly comparable for two reasons. One, the domain of allowable parameter values for the SKU specific residuals ResEffect ${ }^{(S K U)}$ is different from that of ResEqty ${ }^{(S B)}$ and ResEqty ${ }^{(B R D)}$. A workaround is we contrast the absolute values of the logs of each level's ResEqty ${ }^{13}$ to effect a comparison. Two, there exist gaps and missing branding levels in the branding structure for many brands. Again, to ensure comparability, we use only those subbrands that are distinct from their master brands in calculating the average contribution by branding level. We find that the SKU level, through $\left|\xi^{(S K U)}\right|$ contributes $36.98 \%$ to total RE, the sub-brand level through $\left|\xi^{(S B)}\right|$ contributes $35.6 \%$, and the brand level, through $\left|\xi^{(B R D)}\right|$, contributes $27.4 \%$. The relatively high revenue impact of SKU level residual effect is accounted for at least in part by the likely presence of latent, non-unique product attributes at the SKU level. The sub-brand level's contribution to total RE is greater than that of the brand level, suggesting that on the average, sub-brands exert greater influence on revenues than brands do. Some support for this finding comes from the trade press for the beer industry (see, e.g., the Adams Beer Handbook) that refers to sub-brands as de facto 'brands', and appears to treat sub-brands as the organizing units in the beer category. Consequently, beer sales reporting and analysis are seldom aggregated to the master brand level. The implication seems to be that, at least in the beer category managerial attention should be prioritized towards the better management of SKUs and subbrands because the potential gain in market response is highest here.

We next discuss in some detail the ResEqty results for sub-brands and brands. Table 4 displays the ResEqty of different branding levels and computes the ResEqty Multiplier (or REM) and associated

\footnotetext{
${ }^{13}$ Since the location parameter of the DP base distribution in all levels is 0 , deviation from 0 would provide some idea of ResEqty strength.
} 
revenue dollar premium. The mean of the posterior MCMC draws is taken as the ResEqty point estimate at each level. ResEqty values credibly nonzero under a 90\% Highest Probability Density (HPD) interval criterion are marked in bold font. ResEffect ${ }^{(S K U)}$ information for the 272 SKUs is summarized in column (8) as the revenue-weighted ResEqty across the sub-brand's SKUs.

At least four interesting observations and implications emerge from the information in Table 4.

One, solely in terms of ResEqty ${ }^{(B R D)}$, Pacifico Clara, a niche Mexican import sold in states bordering Mexico and targeted at the Hispanic community tops the table by a wide margin. It is followed by Australian import Fosters, Dutch import Amstel Light, Mexican import Corona and Dutch import Heineken. The case of Pacifico Clara is particularly striking in that despite very low advertising, merchandizing, promotions, relatively low distribution levels and number of SKUs, it has carved a niche image and lasting brand appeal among its targeted audience. Whereas at first glance, imported brands in the super-premium price-class ${ }^{14}$ would all seem to enjoy high ResEqty, the presence of high priced imports with low ResEqty (Becks, Dos Equis, Modelo Especial, Labatt, Tecate) suggests otherwise. The foreign imports are then followed closely by the mainstream, mass-market US brands Coors and Budweiser in the brand ResEqty terms. Here too, the presence of relatively high-priced but low ResEqty brands such as George Killian's Irish Red and Michelob suggests that brand ResEqty does not seem to be driven by some unobserved quality attribute alone. Further, we reiterate that the ResEqty measure is estimated independent of brand size and so, brand size is also not the driving factor either. These results are consistent with the notion of brand equity as a multidimensional construct (Aaker 1991).

Two, ResEqty spread across the branding structure is non-uniform and often tends to concentrate at a particular level. For instance, whereas on the one hand, ResEqty concentrates at the brand level in Budweiser and Coors in that their ResEqty ${ }^{(B R D)}$ is significantly higher than their individual ResEqty ${ }^{(S B)}$, on the other, in Miller and Keystone, sub-brands retain the bulk of branding associations as measured by

\footnotetext{
${ }^{14}$ Adam's Beer Handbook classifies sub-brands into one of three prices-classes, namely, super-premium, premium and popular, in the descending order of average price per fluid ounce.
} 
ResEqty. Whereas the former case is intuitive in that sub-brand identities are subordinated to the driver role of the master brand typically seen in many CPG categories (Aaker, 2004), the latter case implies that sub-brand identities dominate that of the master brand. One explanation, in the case of Miller, is that the sub-brands span both the premium (Miller Genuine Draft) as well as the popular price class (Miller high Life) thereby diluting master brand identity. Then, there are brands like Heineken, Natural, Michelob and Corona that have a significant ResEqty mass at both the brand and sub-brand levels. The implication is that regardless of which branding element was intended to have a driver role (Aaker, 2004), aggregate revealed preference data point to where in the brand hierarchy for any particular product, equity actually resides, and in what magnitude. Thus for example, managers can decide if a strong master brand with weak-sub-brands (in ResEqty terms) may benefit more from advertising or trade promotions at the brand level rather than at the sub-brand level. If line extensions or brand extensions are being planned, then information on realized ResEqty can be valuable in deciding the form of the line extension (whether subbrand, endorsed brands, or other branded differentiators), and in assessing the fit with the target category in the case of a brand extension.

Three, there appears to be considerable heterogeneity in ResEqty ${ }^{(S B)}$ values within a brand. The information in Table 4 would help better assess the relative attractiveness and strength of the sub-brand identity independent of the size of the sub-brand. Thus for example, in the 5 Miller sub-brands, Miller High Life Light has the highest ResEqty at 2.14 but is the second smallest of Miller's sub-brands. The ResEqty information would be a valuable input to managerial decisions such as whether to invest in the growth of Miller High Life Light against that of another sub-brand.

Four, in 18 of the 56 sub-brands in the sample, the weighted ResEffect ${ }^{(\mathrm{SKU})}$ is below 1 implying that the choice of SKUs and the set of branding associations and latent SKU attributes that go with the SKU, is poor. Three of the lowest SKU residual effect items are Coors 20-pack 12 oz bottles, Labatt Blue 24-pack $12 \mathrm{oz}$ cans, and a 6-pack $12 \mathrm{oz}$ of Michelob Honey Lager whereas 3 of the highest ResEffect $^{(S K U)}$ items are a 12-pack 12 oz bottles of Corona Extra and Heineken, and a 6-pack 16 oz of 
Natural Ice. Since, in our model, SKU residual effect emerges after all observed attributes in the data have been accounted for, we can't know from the SKU descriptors what particular latent or unobserved attributes are driving the estimated SKU residual effect value. Firms might consider changing packaging, benchmarking against close competitors who are doing well, revamping the positioning of sub-brands and other such actions in such cases.

Since the simple fixed effect as brand equity model is widely known and used, a comparison with our ResEqty specification would be in order. We define two fixed effects, or FEs, termed Ln (Brand FE) and Ln (Sub-brand FE) that are estimated separately and compared with their corresponding ResEqty terms. The FE terms are obtained by projecting the log of revenue over brand and sub-brand dummies respectively and over all observed explanatory variables that are not multi-collinear with the respective FE terms. By construction, these FE models do not explicitly incorporate the revenue influence of the rest of the branding structure. Thus, the Brand FE model would exclude ResEqty ${ }^{(S B)}$ and ResEffect ${ }^{(S K U)}$ information entirely but would include the confounding effect of $\mathbf{X}^{(B R D)}$ from (15) into Brand FE. Similarly, Sub-brand FE excludes ResEffect ${ }^{(S K U)}$ but includes the confounding effect of $\mathbf{X}^{(S B)}$ and $\mathbf{X}^{(B R D)}$ from (15) into Sub-brand FE. The ResEqty terms were estimated under a non-negativity domain restriction. For comparability, a simple transformation of the FE terms ensures the same holds. So, for Ln (Brand $\mathrm{FE}_{b}$ ) of brand $b$, we impose the non-negativity constraint, ex-post, as:

$$
\operatorname{Ln}\left(\operatorname{Brand~}_{\mathrm{FE}_{b}^{*}}\right)=\operatorname{Ln}\left(\operatorname{Brand~FE}_{b}\right)-\operatorname{Min}_{i}\left\{\operatorname{Ln}\left(\operatorname{Brand~FE}_{i}\right)\right\}
$$

and obtain $\operatorname{Ln}\left(\right.$ Brand $\left.\mathrm{FE}^{*}\right) \geq 0$. We do likewise for sub-brand FE and obtain $\mathrm{Ln}$ (Sub-brand FE* $) \geq 0$.

We find that the mean Brand $\mathrm{FE}^{*}$ is 2.82 against the mean REM at 2.08 and the mean ResEqty $^{(B R D)}$ at 1.89 . Thus, we see that ignoring the branding structure effects on revenue and the confounding effects of non-unique variables $\left(\mathbf{X}^{(B R D)}\right)$ significantly inflates the brand equity estimates. 
The mean sub-brand $\mathrm{FE}^{*}$ is 2.42 compared to the average ResEqty ${ }^{(S B)}$ of 1.27 , again clearly indicating that not accounting for the confounding effect of $\mathbf{X}^{(S B)}$ and $\mathbf{X}^{(B R D)}$ significantly inflates brand equity.

\subsection{Brand Valuation}

Aaker (1991) lists four bases for brand valuation and terms brand value based on future earnings the 'best' one. The availability of the brand asset's earnings in the form of the revenue dollar premium provides a natural segue towards brand valuation based on future earnings. Brand valuation in this context enables us to test whether the resQty Multiplier (or REM) estimates bear relation to reality, and whether they can be validated against information from independent, external sources. In particular, two compelling examples of the external validity for the proposed approach come from comparisons with brand valuations based on financial data. These are Interbrand Inc's brand valuation for Budweiser published in Business Week (2005), and the actual acquisition price paid for Miller Brewing's brand assets.

We now detail the case of Miller Brewing as shown in Table 6. South African Breweries (SAB) merged with the Miller Brewing Company in 2001 to create the world's second largest brewing company (behind Anheuser-Busch). At that time, SAB Miller listed the goodwill of its Miller assets at $\$ 4.25$ billion. This goodwill principally represents the net present value of the various Miller brands' brand equities. In Table 6, we take the annual Revenue Dollar Premiums for the Miller Brewing Company's brands (Miller, Milwaukee's Best and Icehouse) at \$ 394.8 million per year from Table 5 as representing the brands' yearly revenue contribution at retail grocery outlets. We then adjust this figure to account for retail mark-ups, retail sales through non-grocery channels, on-premises (bar and pub) sales and non-US sales of slightly over a tenth of total sales. We subtract the average yearly advertising expense from the brand's cash flow ${ }^{15}$. Consequently an annual brand equity figure of $\mathbf{\$} \mathbf{3 4 7 . 7}$ million which when discounted in perpetuity using a discount rate of $7.3 \%$ (the rate used by SAB Miller in their calculations and filed with the SEC) provides a net present value estimate for the brand equity of the Miller brand

\footnotetext{
${ }^{15}$ We model advertising effects on sales as contemporaneous (i.e. one year's advertising primarily affects that year's sales) and assume a degree of stationarity in the advertising levels of major, established brands.
} 
portfolio of $\$ \mathbf{4 . 7 6}$ billion. This brand value estimate seems to be within the ballpark of the actual price paid, namely, $\$ 4.25$ billion.

The brand consultancy InterBrand, after consulting with industry analysts, company executives and the company account books, estimated the brand value of Budweiser at $\$ 11.93$ billion in 2005. In Table 11, we again use the REM annual Revenue Dollar Premium for the Budweiser brand $\mathbf{\$} \mathbf{9 8 5 . 5}$ million from Table 5) as the yearly value of the brand at retail grocery outlets, and adjust the figure to account for other factors not in the analysis data, as was done for Miller's brands. Assuming a discount factor of $10.7 \%{ }^{16}$, we arrive at a global brand value for Budweiser of $\$ \mathbf{1 2 . 9 4}$ billion. Once again, despite rough cut calculations, broad assumptions and entirely different methods and data sources, our brand valuation figure is comparable to that from InterBrand. Hence, the proposed REM measure appears to bear external validity.

Thus, overall, there is reason to believe that compared to alternative specifications, the proposed REM measure is indeed a more realistic estimate of branding structure equity contribution to revenue. It agrees with valuation information from external, independent sources and is thereby externally validated.

The ease with which brand valuation can be conducted using revenue dollar premium estimates leads us to estimate the brand values (for the US market only) for the remaining brands in the sample. We use a discount rate of $10.7 \%$ for Anheuser-Busch brands, $7.3 \%$ for SABMiller brands (from the valuation exercise carried out previously) and assume a discount rate of $10 \%$ for the remaining brands. Hence the brand values are illustrative only ${ }^{17}$. Table 5 lists the results in descending order of brand value.

In 1999, the Marketing Science Institute had identified ten desiderata for measures of brand equity. We argue that that the proposed ResEqty multiplier measure meets nine of those ten criteria in that it is intuitive, credible, objective, grounded in theory, based on readily available data, a singlenumber measure (which facilitates easier tracking and communication), robust and stable, reasonably

${ }^{16}$ We arrive at a discount rate of $10.7 \%$ for Anheuser-Busch by using (i) a risk-free rate of $5 \%$ (close to the historical average), (ii) Anheuser-Busch's stock beta of 0.62 (Yahoo company profiles) as a proxy for risk, and (iii) a long term market risk premium of $9.2 \%$ (Bowman, 2001).

${ }^{17}$ For Labatt, the advertising spend exceeds revenue dollar premium. So, to avoid a negative net brand value, we ignore ad-spend in the computation of Labatt's brand value. 
complete (in that it along with its downstream measure - the revenue dollar premium - captures both the depth and the size facets of Brand Equity), and able to assess the potential of future marketing outcomes (as brought out in the brand valuation exercise). As for the tenth criterion, akin to other product-market measures, the REM is diagnostic only to the extent that it can identify changes in brand equity over time or differences across brands.

\section{$7 \quad$ Managerial Implications and Conclusion}

Managers have long felt the need for a reliable brand equity measurement system (Keller and Lehmann, 2006) and the proposed approach represents a step forward in constructing a BE measurement system that overcomes key problems in extant measurement schemes. Our proposed nonparametric Bayesian model leverages the benefits of a fixed effects approach, such as simplicity, robustness, ability to capture any heterogeneity pattern and non-reliance on any distributional assumptions while avoiding attribute confounds from other levels in the branding hierarchy. These benefits are coupled with the added advantage that the proposed model applies even when the number of observations available is rather limited (for instance, in cross-sectional analyses), and when ex-ante domain and parameter restrictions need to be built into the model, The model, demonstrated on the beer category, relies on readily accessible aggregate sales data, explicitly accounts for contributions to marketing outcomes from individual layers in a complex branding structure, and makes enables brand valuation that find validation from external, independent sources.

Several implications of academic and practical interest emerge. First, this study brings out importance of understanding and explicitly accounting for the sales contribution from every level in the branding structure in order to more accurately arrive at brand and sub-brand equity. We find that ignoring the confounding effect of non-unique product attributes inflates equity estimates.

Second, the study demonstrates the existence and credibility of residual equity, defined here as the impact on market response due to latent, unique branding structure attributes, at both the sub-brand and the brand level. Further, we find there is considerable heterogeneity in the RE values between brands as well as the RE values among sub-brands within a brand. The proposed model enables assessment of 
equity at each individual brand and sub-brand level and thereby promises to aid in the audit and the management of brand portfolios. On the average, we find that the relative contribution of the SKU level to market response is higher than that of sub-brands and of brands. Hence, given limited firm resources and management attention, management of SKUs and sub-brands should be prioritized for maximal impact on market response.

Third, the dollar-metric Revenue Dollar Premium measure derived from the REM measure yields reasonable brand valuations. Correspondingly, these easily estimated premiums have a direct application to situations that require financial valuations of equity at the brand level. This is propitious since standard financial, stock market and accounting data are typically at the firm level and, thus, not fully appropriate. Hence, the methodology appears to be appropriate for brand valuations which are central to mergers and acquisitions and, more broadly, to organizational arrangements that require a limited transfer of rights to a brand name for a period of time or in particular geographic area, such as franchising contracts and brand alliances. At a more mundane level, tracking a product line's RE and Dollar Premiums over time at different branding and product aggregation levels provides a simple running diagnostic of a product's "health" and the success of its branding program.

The study can be extended to a number of avenues for future research. One is generalizing the branding structure to more complex schemes such as umbrella branding, as ingredient branding, cobranding, and endorsement valuation and $\mathrm{BE}$ assessment issues in a variety of organizational arrangements (e.g., franchising, brand alliances and Private Labels). Another is exploiting the discreteness property of the Dirichlet Process Mixture method to develop newer models of inter-product competition based on the residual equity from branding structures which is a latent or unobserved attribute. A third avenue relates to developing random parameter models for marketing mix response using a multivariate Dirichlet Process specification.

The model as applied has certain limitations. One caveat is that the model is reduced-form and hence counter-factual experiments cannot be performed with it. Another is that the REM is diagnostic only to the extent that it can identify changes in equity over time or differences across brands. A third 
limitation is that the economic restrictions incorporated apply readily only to established brands in mature categories and would not be appropriate in new product situations. Fourth, the model is data driven, so finer data and better instrumental variables can always help to improve the estimates. 


\section{Bibliography}

Aaker, D. (1991), Managing Brand Equity. New York Free Press, New York. (2004), Brand Portfolio Strategy, New York Free Press, New Yrok.

$\overline{\text { Review, } 38}$ (Spring), 102-120.

(1996), "Managing Brand Equity Across Products and Markets", California Management and R. Jacobson (1994), “The Financial Information Content of Perceived Quality”, Journal of Marketing Research, 31(2), 191-201.

Adams Beer Handbook (2002-2006), Bev-Al Communications, Norwalk, CT.

Allenby, G., Arora, N. and J. Ginter (1998), “On the Heterogeneity of Demand”, Journal of Marketing Research, 35(3), 384-389.

Ailawadi, K., Lehmann, D. and S. Neslin (2003), "Revenue Premium as an Outcome Measure of Brand Equity", Journal of Marketing Research 67, (October), 1-17.

Andrews, R.L. and I. Currim (2003), “A Comparison of Segment Retention Criteria for Finite Mixture Models", Journal of Marketing Research, 40(2), 235-243.

Antoniak, C.E. 1974. Mixtures of Dirichlet Processes with Applications to Nonparametric Problems. Annals of Statistics, 2(4):1152-1174.

Bhat, S. and S. Reddy (2001), "The Impact of Parent Brand Attribute Associations and Affect on Brand Extension Evaluation", Journal of Business Research, 53(3), 111-122.

Bousch, D. Shipp, S., Loken, B., Genturck, E., Crockett, S., Kennedy, E., Minshall, B., Misurell, D., Rochford, L. and J. Strobehl (1987), “Affect Generalization to Similar and Dissimilar Brand Extensions", Psychology and Marketing, 4(Fall), 225-237.

Bowman, R.G. (2001), "Estimating the Market Risk Premium: The Difficulty with Historical Evidence and an Alternate Approach", JASSA, Issue 3 (Spring), 10-13.

Celeux, G., M. Hurn, and C. P. Robert (2000), “Computational and Inferential Difficulties with Mixture Posterior Distributions," Journal of the American Statistical Association, 95, 451, 957-970.

Chaudhari, A. and M. Holbrook (2001), "The Chain of Effects from Brand Trust and Brand Affect to Brand Performance: The Role of Brand Loyalty”, Journal of Marketing, 65 (April), 81-93.

Draper, David (1999), Discussion on "Bayesian Nonparametric Inference for Random Distributions and Related Functions". Journal of the Royal Statistical Society, Series B 61(3):510—513.

Dubin, J. (1998), "The Demand for Branded and Unbranded Products: An Econometric Method for Valuing Intangible Assets", Chapter 4 in Studies in Consumer Demand: Econometric Methods Applied to Market Data, Norwell, MA. Kluwer Academic Publishers, 77-127.

Erdem, T. (1998), “An Empirical Analysis of Umbrella Branding”, Journal of Marketing Research, 35(3), 339-351. 
Ishwaran, H. and M. Zarepour (2002), "Markov Chain Monte Carlo in approximate Dirichlet and two parameter process hierarchical models", Biometrika, 87, p. 371-390.

(2002), "Exact and Approximate Sum Representations for the Dirichlet Process", Canadian Journal of Statistics, 30(2), p. 269-283.

Ferguson, T.S. (1973), A Bayesian analysis of some nonparametric problems". In Annals of Statsistics, 1, 209-230..

(1983), Bayesian Density Estimation by Mixtures of Normal Distributions. In Recent advances in statistics, ed. H. Rizvi and J. Rustagi, 287-302. New York: Academic Press.

Ghosh, P., Basu, S., and Tiwari, R.C. (2009), "Bayesian Analysis of Cancer Rates from SEER Program Using Parametric and Semiparametric Joinpoint Regression Models", Journal of the American Statistical Associatio, 104, 439-452.

Goldfarb, A., Lu, Q. and S. Moorthy (2009) "Measuring Brand Value in an Equilibrium Framework", Marketing Science. 28(1), 69-86.

Guadagni, P. and J. Little (1983), "A Logit Model of Brand Choice Calibrated on Scanner Data", Marketing Science, 2, 203-238.

Haig, M., (2005), Brand Failures, Kogan Page Publishers, UK.

Hoch, S., Kim, B., Montgomery, A. and P. Rossi (1995), "Determinants of Store-Level Price Elasticity", Journal of Marketing Research, 32(1), 17-29.

Horsky, D. and P. Nelson (1992), "New Brand Positioning and Pricing in an Oligopolistic Market", Marketing Science. 11(2), 133-153.

Interbrand BusinessWeek Brand Survey (2005), Best Global Brands 2005,

URL: http://www.ourfishbowl.com/brand_val/best_brands_05/2005_rankings_dollars.pdf

Kamakura, W. and G. Russell (1993), "Measuring Brand Value with Scanner Data", International Journal for Research in Marketing, 10(1), 9-22.

Keller, K. and D. Lehmann (2003), "The Brand Value Chain: Optimizing Strategic and Financial Brand Performance”, Marketing Management, (May/June), 26-31.

Marketing Science, 25(6), 740-759.

(2006), "Brands and Branding: Research Findings and Future Priorities",

Kim, Jin Gyo, Ulrich Menzefricke, and Fred M. Feinberg. 2004. Assessing heterogeneity in discrete choice models using a dirichlet process prior. Review of Marketing Science 2(1):1-39.

Lilien, G., Kotler, P. and S. Moorthy (1992), Marketing Models, Prentice-Hall, NJ.

Little, J. (1979), “Aggregate Advertising Models: The State of the Art”, Operations Research, 27(4), 629667. 
Mahajan, V., Rao, V. and R. Srivastava (1994), “An Approach to Assess the Importance of Brand Equity in Acquisition Decisions", Journal of Product Innovation Management, 11(3), 221-235.

Marketing Science Institute (1999), "Value of a Brand", Workshop at Marketing Science Institute Conference on Marketing Metrics, Washington DC (October 6-8).

Ohlssen D., Sharples, L. and D. Spiegelhalter (2007), "Flexible random-effects models using Byesian semi-parametric models: Application to institutional comparisons", Statistics in Medicine. 26, 2088-2112.

Roeder, K.(1994), “A Graphical Technique for Determining the Number of Components in a Mixture of Normals," Journal of the American Statistical Association, 89, 426, 487-495.

SABMiller (2002) Annual Report, Consolidated Financial Statements,

URL: http://sabmillerstaging.framfab.co.uk/sabmiller.com/en_gb/Investors/Annual+reports/

Sethuraman, J. 1994. A Constructive Definition of Dirichlet Priors. Statistica Sinica, 4(2):639—650.

Sethuraman, R., (2003), "Measuring National Brands' Equity over Store Brands", Review of Marketing Science, Vol. 1, Article 2."

Simon, C. and M. Sullivan (1993), "The Measurement and Determinants of Brand Equity: A Financial Approach", Marketing Science, 12, (Winter), 28-52.

Spiegelhalter, D., Thomas, A. and N. Best (2003), WinBUGS User Manual. Version 1.4. Cambridge: MRC Biostatistics Unit.

U.S. Census Bureau, Population Division, (2006), "Monthly Population Estimates for the United States: April 1, 2000 to October 1, 2006", NA-EST-2005-01.

Yahoo Finance, Anheuser-Busch Company profile, Keys Statistics Section, Stock Beta, URL: $\mathrm{http}: / /$ finance.yahoo.com/q/ks?s=BUD 
Table 1. U.S. Beer Market, Summary of Variables

\begin{tabular}{|c|c|c|c|c|}
\hline Level & Variable $^{a}$ & Description & Mean (s.d.) & Source \\
\hline & Ln(Revenuejt) & $\log$ of revenue for SKU $j$ in period $t$ & $13.4(1.2)$ & Scanner Data \\
\hline \multirow{2}{*}{ Product } & Craft $v_{v}$ & Craft type $=1$, otherwise $=0$ & 0.04 & \\
\hline & Dry v & Dry type $=1$, otherwise $=0$ & 0.01 & Scanner \\
\hline Beer & Ice $_{v}$ & Ice type $=1$, otherwise $=0$ & 0.12 & Data \\
\hline \multirow[t]{2}{*}{ Type } & Lite $_{\mathrm{v}}$ & Lite type $=1$, otherwise $=0$ & 0.4 & \multirow[t]{2}{*}{ (AC Nielsen) } \\
\hline & ${\underline{\text {Regular}_{\mathrm{v}}}}$ & Regular type $=1$, otherwise $=0$ & 0.43 & \\
\hline \multirow{3}{*}{$\begin{array}{l}\text { Origin } \\
\text { Alchohol\% }\end{array}$} & Imported $_{v}$ & Imported brewer $=1$, otherwise $=0$ & 0.06 & \multirow{2}{*}{ The Internet } \\
\hline & $\mathrm{ABV}_{\mathrm{v}}$ & $\%$ Alchohol by Volume & $4.71(0.6)$ & \\
\hline & Amber $_{v}$ & Amber color $=1$, otherwise $=0$ & 0.05 & \multirow{4}{*}{ Scanner Data } \\
\hline Beer & Light $_{\mathrm{v}}$ & Light color $=1$, otherwise $=0$ & 0.74 & \\
\hline Color & Golden v & Golden color $=1$, otherwise $=0$ & 0.19 & \\
\hline \multirow{7}{*}{ Packaging } & Darkv & Dark color $=1$, otherwise $=0$ & 0.01 & \\
\hline & $\mathrm{Can}_{\mathrm{j}}$ & Can $=1$, otherwise $=0$ & 0.47 & \multirow[t]{6}{*}{ Scanner data } \\
\hline & Bottle $_{j}$ & Bottle $=1$, otherwise $=0$ & 0.53 & \\
\hline & Sixpackj & Sold in packs of $6=1$, else $=0$ & 0.31 & \\
\hline & Twelvepack $\mathrm{j}$ & Sold in packs of $12=1$, els $\mathrm{e}=0$ & 0.30 & \\
\hline & Case $_{j}$ & 18 pack and above $=1$, els $\mathrm{e}=0$ & 0.26 & \\
\hline & $\mathrm{Oz}_{\mathrm{j}}$ & Total SKU volume in ounces & $141.51(91.4)$ & \\
\hline \multirow[t]{3}{*}{ Promotion } & AdSpend $_{v t}$ & Annual Ad spend in \$ million & 30.61 & LNA $^{\mathrm{b}}$ \\
\hline & Competition $_{\mathrm{jt}}$ & Inter-product competition levels & $-6149(625)$ & \multirow{2}{*}{ Scanner Data } \\
\hline & $\% \mathrm{ACV}^{\mathrm{b}}$ Merchandizing $_{\mathrm{jt}}$ & $\% \mathrm{ACV}$ that promoted the SKU & $12.47(13.3)$ & \\
\hline \multirow[t]{2}{*}{ Distribution } & $\% \mathrm{ACV}^{\mathrm{b}}$ Distribution $_{\mathrm{jt}}$ & $\% \mathrm{ACV}$ that carried the SKU & $30.52(22)$ & \multirow{2}{*}{ Scanner Data } \\
\hline & SKUnum $_{\mathrm{vt}}$ & Average number of SKUs in the variant & $7.87(4.6)$ & \\
\hline Category & AdultPop $t_{t}$ & US population over 21 years old in millions & $206.6(2.9)$ & Bureau of \\
\hline \multirow[t]{12}{*}{ Drivers } & FreightPPI $t$ & Long haul freight $\mathrm{PPI}^{\mathrm{b}}$ & $4.74(0.05)$ & Labor Statistics \\
\hline & CanadaRate $\mathrm{t}$ & Canadian dollar exchange rate per US dollar & 1.37 & \multirow{3}{*}{ US Federal Reserve } \\
\hline & PesoRate $\mathrm{t}$ & Mexican peso exchange rate per US dollar & 10.6 & \\
\hline & EuroRate $_{\mathrm{t}}$ & Euro exchange rate per US dollar & 1.13 & \\
\hline & Winter $t$ & Winter $=1$, otherwise $=0$ & 0.24 & \multirow{8}{*}{ Scanner Data } \\
\hline & Fall $\mathrm{t}$ & Fall $=1$, otherwise $=0$ & 0.24 & \\
\hline & Spring $_{t}$ & Spring $=1$, otherwise $=0$ & 0.23 & \\
\hline & Summer $\mathrm{t}$ & Summer $=1$, otherwise $=0$ & 0.29 & \\
\hline & Year $2002 \mathrm{t}$ & Year $2002=1$, otherwise $=0$ & 0.26 & \\
\hline & Year $2003 \mathrm{t}$ & Year $2003=1$, otherwise $=0$ & 0.25 & \\
\hline & Year $2004 \mathrm{t}$ & Year $2004=1$, otherwise $=0$ & 0.23 & \\
\hline & Year $2005 \mathrm{t}$ & Year $2005=1$, otherwise $=0$ & 0.27 & \\
\hline
\end{tabular}

${ }^{\text {a }}$ Subscripts $j, v, b, t$ denote SKU, sub-brand, brand and period respectively.

'LNA stands for Leading National Advertisers, ACV for 'All Commodity Volume', 'PPI' for Purchasers Price Index. 
Table 2. U.S. Beer Market, Summary Statistics by Brand

\begin{tabular}{|c|c|c|c|c|c|c|}
\hline B rand $^{\mathrm{a}}$ & Supplier & $\begin{array}{c}\text { Revenue } \\
\text { Share }\end{array}$ & $\begin{array}{c}\text { Average } \\
\text { Price } \\
(\$ / 0 z) \\
\end{array}$ & $\begin{array}{c}\text { Average }^{\mathrm{b}} \\
\% \mathrm{ACV} \\
\text { Distribution }\end{array}$ & $\begin{array}{c}\text { Average }^{\mathrm{b}} \\
\% \mathrm{ACV} \\
\text { Merchandizing }\end{array}$ & $\begin{array}{l}\text { AdSpend }^{\mathrm{c}} \\
\$ M n \\
\text { per year } \\
\end{array}$ \\
\hline Budweiser & Anheuser-Busch & $29.58 \%$ & 0.060 & 56.3 & 20.7 & 267.1 \\
\hline Miller & SABMiller & $14.70 \%$ & 0.054 & 49.3 & 17.0 & 192.4 \\
\hline Coors & Molson Coors & $9.09 \%$ & 0.060 & 53.0 & 21.6 & 147.5 \\
\hline Corona & Barton Gambrinus & $8.60 \%$ & 0.098 & 72.1 & 35.7 & 43.1 \\
\hline Michelob & Anheuser-Busch & $6.12 \%$ & 0.067 & 56.2 & 18.5 & 73.9 \\
\hline Busch & Anheuser-Busch & $5.40 \%$ & 0.046 & 34.4 & 11.1 & 12.3 \\
\hline Natural & Anheuser-Busch & $4.85 \%$ & 0.044 & 46.6 & 13.9 & 0.1 \\
\hline Heineken & Heineken Usa & $4.15 \%$ & 0.097 & 68.2 & 32.3 & 50.4 \\
\hline Milwaukee's Best & SABMiller & $3.36 \%$ & 0.037 & 38.2 & 7.0 & - \\
\hline Keystone & Molson Coors & $1.55 \%$ & 0.041 & 24.6 & 7.1 & 2.4 \\
\hline Sam Adams & Boston Beer & $1.34 \%$ & 0.096 & 47.5 & 18.0 & 29.3 \\
\hline Tecate & InBev USA & $1.25 \%$ & 0.065 & 21.4 & 10.1 & 2.7 \\
\hline Labatt & InBev USA & $1.14 \%$ & 0.062 & 18.3 & 5.9 & 12.8 \\
\hline Icehouse & SABMiller & $1.10 \%$ & 0.049 & 19.6 & 6.2 & 1.8 \\
\hline Old Milwaukee & Pabst Brewing & $1.02 \%$ & 0.039 & 20.4 & 3.0 & 0.1 \\
\hline Becks & InBev USA & $0.96 \%$ & 0.087 & 44.1 & 18.2 & 9.1 \\
\hline Rolling Rock & InBev USA & $0.80 \%$ & 0.067 & 61.1 & 20.1 & 5.3 \\
\hline Amstel & Heineken Usa & $0.75 \%$ & 0.101 & 52.9 & 25.6 & 21.1 \\
\hline Pabst & Pabst Brewing & $0.74 \%$ & 0.040 & 25.7 & 5.7 & 0.3 \\
\hline Molson & Molson Coors & $0.70 \%$ & 0.061 & 18.3 & 4.4 & 3.6 \\
\hline Fosters & SABMiller & $0.66 \%$ & 0.079 & 53.0 & 14.4 & 5.9 \\
\hline George Killians & USA & $0.54 \%$ & 0.076 & 55.8 & 21.0 & - \\
\hline Dos Equis & InBev USA & $0.54 \%$ & 0.091 & 37.3 & 11.6 & 4.7 \\
\hline Modelo Especial & Barton Gambrinus & $0.53 \%$ & 0.085 & 23.1 & 5.7 & 1.7 \\
\hline Pacifico Clara & Barton Gambrinus & $0.52 \%$ & 0.090 & 27.5 & 9.0 & 1.7 \\
\hline Mean & & $4.00 \%$ & 0.068 & 41.0 & 14.5 & 35.6 \\
\hline Std dev & & $6.39 \%$ & 0.065 & 16.8 & 8.7 & 5.3 \\
\hline
\end{tabular}

Sorted in descending order by revenue share.

${ }^{b}$ Revenue weighted average over the brand's SKUs over te entire sample period.

${ }^{\mathrm{c}}$ Average yearly advertising spend 
Table 3: Main Effects Estimates in Equation (8)

\begin{tabular}{|c|c|c|c|c|}
\hline Factor $^{\mathrm{a}}$ & Variable $^{\mathrm{b}}$ & Estimate & $2.5 \%$ Interval & $97.5 \%$ Interval \\
\hline & Intercept & -3.90 & -3.91 & -3.89 \\
\hline \multirow{2}{*}{ Product } & Craft & -0.01 & -0.07 & 0.08 \\
\hline & Dry & -0.53 & -0.63 & -0.43 \\
\hline Beer & Ice & 0.09 & 0.06 & 0.11 \\
\hline \multirow[t]{2}{*}{ Type } & Lite & 0.45 & 0.43 & 0.47 \\
\hline & Regular & & Reference Type & \\
\hline Origin & Imported & 0.08 & 0.05 & 0.11 \\
\hline \multirow[t]{3}{*}{ Alchohol\% } & $\mathbf{A B V}$ & 0.54 & 0.53 & 0.54 \\
\hline & $\mathbf{A B V}^{2}$ & -0.03 & -0.03 & -0.03 \\
\hline & Amber & 0.63 & 0.53 & 0.69 \\
\hline Beer & Light & 0.59 & 0.57 & 0.60 \\
\hline \multirow[t]{5}{*}{ Color } & Golden & 0.55 & 0.51 & 0.58 \\
\hline & Dark & & Reference Color & \\
\hline & Can & 0.12 & 0.11 & 0.14 \\
\hline & Bottle & & erence Container T & \\
\hline & Singlepk & 0.22 & -0.16 & 0.61 \\
\hline \multirow[t]{6}{*}{ Packaging } & Sixpack & 0.74 & 0.72 & 0.75 \\
\hline & Twelvepack & 0.44 & 0.43 & 0.46 \\
\hline & Case & 0.30 & 0.29 & 0.32 \\
\hline & NonstdPk & & rence Packaging ? & \\
\hline & $\mathbf{O z}$ & 0.02 & 0.02 & 0.02 \\
\hline & $\mathrm{Oz}^{2}$ & 0.00 & 0.00 & 0.00 \\
\hline \multirow[t]{3}{*}{ Promotion } & Ln \% ACV Merchandizing & 0.16 & 0.16 & 0.17 \\
\hline & Competition & -0.09 & -0.09 & -0.09 \\
\hline & Ln Ad Spend & 0.02 & 0.02 & 0.02 \\
\hline \multirow[t]{2}{*}{ Distribution } & Ln \% ACV Dis tribution & 0.96 & 0.96 & 0.96 \\
\hline & Ln SKUnum & 0.12 & 0.11 & 0.12 \\
\hline \multirow[t]{11}{*}{ Category Drivers } & Ln AdultPop & 1.05 & 1.05 & 1.05 \\
\hline & FreightPPI & 0.70 & 0.70 & 0.70 \\
\hline & ExchgRate & 0.10 & 0.09 & 0.12 \\
\hline & Fall & -0.16 & -0.16 & -0.15 \\
\hline & Winter & -0.15 & -0.16 & -0.14 \\
\hline & Spring & -0.13 & -0.13 & -0.12 \\
\hline & Summer & & Reference Season & \\
\hline & Year2002 & 0.28 & 0.28 & 0.29 \\
\hline & Year2003 & 0.18 & 0.17 & 0.18 \\
\hline & Year2004 & 0.10 & 0.09 & 0.10 \\
\hline & Year2005 & & Reference Year & \\
\hline Fit & Error Variance & 0.0183 & 0.018 & 0.0187 \\
\hline Statistics & RMSE & 0.1352 & 0.135 & 0.1354 \\
\hline
\end{tabular}

a. Groups of related variables as written in the model equation.

b. Bold font if estimate's $95 \%$ credibility interval excludes zero. 
Table 4: Residual Equity Estimates in the Branding Structure

\begin{tabular}{|c|c|c|c|c|c|c|c|}
\hline (1) & $(2)$ & (3) & (4) & (5) & $(6)$ & $(7)$ & (8) \\
\hline Brand & $\begin{array}{c}\text { Res Eqty }^{(B R D)} \\
{[95 \%} \\
\text { Interval] }\end{array}$ & Sub-brand & $\operatorname{ResEqty}^{(\mathrm{SB})}$ & REM & $\begin{array}{c}\text { Revenue } \\
\text { \$Mn }\end{array}$ & $\begin{array}{c}\text { Revenue \$ } \\
\text { Premium } \\
\text { \$mn }\end{array}$ & $\begin{array}{c}\text { Weighted } \\
\text { ResEffect }^{(\mathrm{SKU})}\end{array}$ \\
\hline \multirow{5}{*}{ Budweis er } & \multirow{5}{*}{$\begin{array}{c}1.97 \\
{[1.93,2.01]}\end{array}$} & Bud Light & 1.62 & 3.18 & $3,815.82$ & $2,614.8$ & 1.28 \\
\hline & & Budweiser & 1.00 & 1.97 & $2,535.66$ & $1,245.9$ & 1.67 \\
\hline & & Bud Ice & 1.13 & 2.22 & 98.85 & 54.3 & 0.99 \\
\hline & & Bud Ice Light & 1.01 & 1.99 & 27.53 & 13.7 & 0.60 \\
\hline & & Bud Dry & 1.54 & 3.02 & 3.96 & 2.7 & 1.00 \\
\hline \multirow{5}{*}{ Miller } & \multirow{5}{*}{$\begin{array}{c}1.19 \\
{[1.17,1.21]}\end{array}$} & Miller Lite & 1.49 & 1.77 & $1,716.39$ & 749.34 & 1.28 \\
\hline & & Miller High Life & 1.49 & 1.77 & 642.83 & 279.67 & 1.07 \\
\hline & & Miller Genuine Draft & 1.62 & 1.92 & 640.37 & 306.81 & 1.36 \\
\hline & & Miller High Life Lite & 1.48 & 1.75 & 106.21 & 45.68 & 0.56 \\
\hline & & Miller Genuine Draft Lite & 1.29 & 1.53 & 65.29 & 22.72 & 0.52 \\
\hline \multirow{2}{*}{ Coors } & 2.16 & Coors Lite & 2.14 & 4.61 & $1,714.23$ & $1,342.51$ & 0.93 \\
\hline & {$[2.08,2.22]$} & Coors & 1.00 & 2.16 & 255.39 & 137.10 & 0.54 \\
\hline \multirow{2}{*}{ Corona } & 3.41 & Corona Extra & 1.42 & 4.84 & $1,538.08$ & $1,220.25$ & 2.09 \\
\hline & {$[3.28,3.52]$} & Corona Light & 1.42 & 4.84 & 363.57 & 288.39 & 2.43 \\
\hline \multirow{5}{*}{ Michelob } & \multirow{5}{*}{$\begin{array}{c}1.32 \\
{[1.25,1.40]}\end{array}$} & Michelob Ultra Light & 1.06 & 1.40 & 644.10 & 184.72 & 3.81 \\
\hline & & Michelob Light & 1.38 & 1.82 & 398.24 & 179.96 & 1.05 \\
\hline & & Michelob & 1.00 & 1.32 & 158.36 & 38.75 & 1.07 \\
\hline & & Michelob Amber Bock & 1.42 & 1.88 & 99.64 & 46.64 & 0.85 \\
\hline & & Michelob Honey Lager & 1.42 & 1.88 & 8.63 & 4.04 & 1.00 \\
\hline \multirow{3}{*}{ Busch } & \multirow{3}{*}{$\begin{array}{c}1.65 \\
{[1.60,1.71]}\end{array}$} & Busch Light & 1.01 & 1.66 & 582.59 & 231.67 & 1.02 \\
\hline & & Busch & 1.00 & 1.65 & 580.06 & 227.87 & 1.90 \\
\hline & & Busch Ice & 1.42 & 2.34 & 16.13 & 9.23 & 1.00 \\
\hline \multirow{2}{*}{ Natural } & 1.02 & Naural Light & 1.42 & 1.44 & 816.15 & 249.49 & 2.00 \\
\hline & {$[1.001,1.04]$} & Natural Ice & 1.42 & 1.44 & 246.75 & 75.91 & 1.96 \\
\hline \multirow{2}{*}{ Heineken } & 2.16 & Heineken & 1.00 & 2.16 & 900.89 & 483.62 & 2.97 \\
\hline & {$[2.08,2.22]$} & Heineken Dark & 1.42 & 3.06 & 9.27 & 6.24 & 1.00 \\
\hline \multirow{3}{*}{$\begin{array}{l}\text { Milwaukee's } \\
\text { Best }\end{array}$} & \multirow{3}{*}{$\begin{array}{c}1.01 \\
{[1.001,1.04]}\end{array}$} & Milwaukee's Best Light & 1.78 & 1.80 & 311.29 & 138.00 & 0.71 \\
\hline & & Milwaukee's Best & 1.00 & 1.01 & 270.51 & 3.21 & 1.39 \\
\hline & & Milwaukee's Best Ice & 1.38 & 1.40 & 123.33 & 35.02 & 1.77 \\
\hline \multirow{3}{*}{ Keystone } & \multirow{3}{*}{$\begin{array}{c}1.01 \\
{[1.001,1.04]}\end{array}$} & Keys tone Light & 1.90 & 1.92 & 299.72 & 143.61 & 0.76 \\
\hline & & Keystone Ice & 1.42 & 1.44 & 11.63 & 3.55 & 1.00 \\
\hline & & Keystone & 1.00 & 1.01 & 5.08 & 0.06 & 1.00 \\
\hline \multirow{3}{*}{ Sam Adams } & \multirow{3}{*}{$\begin{array}{c}1.65 \\
{[1.60,1.71]}\end{array}$} & Sam Adams Boston Lager & 1.55 & 2.55 & 156.87 & 95.26 & 1.27 \\
\hline & & Samadams Seasonal & 1.30 & 2.14 & 72.32 & 38.49 & 0.77 \\
\hline & & Sam Adams Light & 1.58 & 2.61 & 62.53 & 38.53 & 0.59 \\
\hline Tecate & $\begin{array}{c}1.12 \\
{[1.01,1.2]}\end{array}$ & Tecate & 1.00 & 1.12 & 277.99 & 30.01 & 0.83 \\
\hline Icehouse & $\begin{array}{c}1.10 \\
{[1.001,1.04]}\end{array}$ & Icehouse & 1.00 & 1.10 & 232.10 & 21.48 & 1.21 \\
\hline Labatt & $\begin{array}{c}1.12 \\
{[1.001,1.04]}\end{array}$ & Labatt & 1.00 & 1.12 & 218.64 & 23.95 & 0.49 \\
\hline
\end{tabular}


Table 4 (continued): Residual Equity Estimates in the Branding Structure

\begin{tabular}{|c|c|c|c|c|c|c|c|}
\hline (1) & $(2)$ & (3) & (4) & (5) & (6) & (7) & (8) \\
\hline Brand & $\begin{array}{c}\text { Res Eqty }^{(B R D)} \\
{[95 \%} \\
\text { Interval] }\end{array}$ & Sub-brand & $\operatorname{ResEqty}^{(\mathrm{SB})}$ & REM & $\begin{array}{l}\text { Revenue } \\
\text { \$Mn }\end{array}$ & $\begin{array}{c}\text { Revenue \$ } \\
\text { Premium } \\
\$ \text { mn }\end{array}$ & $\begin{array}{c}\text { Weighted } \\
\text { ResEffect }^{(\mathrm{SKU})}\end{array}$ \\
\hline \multirow{3}{*}{ Becks } & \multirow{3}{*}{$\begin{array}{c}1.324 \\
{[1.25,1.40]}\end{array}$} & Becks & 1.00 & 1.32 & 162.13 & 39.67 & 1.34 \\
\hline & & Becks Dark & 1.53 & 2.02 & 23.59 & 11.94 & 1.23 \\
\hline & & Becks Premium Light & 1.13 & 1.49 & 16.55 & 5.48 & 0.70 \\
\hline \multirow{2}{*}{ Old Milwaukee } & 1.19 & Old Milwaukee & 1.00 & 1.19 & 124.00 & 19.62 & 0.76 \\
\hline & {$[1.17,1.21]$} & Old Milwaukee Light & 1.41 & 1.68 & 54.07 & 21.88 & 0.85 \\
\hline Rolling Rock & $\begin{array}{c}1.32 \\
{[1.20,1.40]}\end{array}$ & Rolling Rock & 1.00 & 1.32 & 170.37 & 40.81 & 2.30 \\
\hline Ams tel Light & $\begin{array}{c}3.40 \\
{[3.28,3.50]}\end{array}$ & Amstel Light & 1.00 & 3.40 & 161.72 & 114.19 & 1.20 \\
\hline Fosters & $\begin{array}{c}5.11 \\
{[4.83,5.45]} \\
\end{array}$ & Fosters & 1.00 & 5.11 & 139.11 & 111.86 & 0.56 \\
\hline Pabst Blue & 1.33 & Pabst Blue Ribbon & 1.00 & 1.33 & 126.56 & 31.04 & 0.99 \\
\hline Ribbon & {$[1.25,1.40]$} & Pabst Blue Ribbon Draft & 1.42 & 1.88 & 10.77 & 5.03 & 0.40 \\
\hline $\begin{array}{l}\text { George Killian's } \\
\text { Irish Red }\end{array}$ & $\begin{array}{c}1.19 \\
{[1.17,1.21]}\end{array}$ & George Killian's Irish Red & 1.00 & 1.34 & 36.61 & 9.32 & 0.76 \\
\hline \multirow{2}{*}{ Dos Equis XX } & 1.12 & Dos Equis Special Lager & 1.43 & 1.59 & 65.12 & 24.17 & 2.20 \\
\hline & {$[1.01,1.19]$} & Dos Equis Xx Amber Lager & 1.42 & 1.58 & 54.15 & 19.97 & 0.51 \\
\hline Modelo Especial & $\begin{array}{c}1.32 \\
{[1.21,1.40]}\end{array}$ & Modelo Especial & 1.00 & 1.32 & 116.31 & 28.33 & 0.83 \\
\hline Pacifico Clara & $\begin{array}{c}7.007 \\
{[6.44,7.74]} \\
\end{array}$ & Pacifico Clara & 1.00 & 7.01 & 111.50 & 95.59 & 0.48 \\
\hline \multirow{3}{*}{ Mols on } & \multirow{3}{*}{$\begin{array}{c}1.19 \\
{[1.17,1.21]}\end{array}$} & Mols on Ice & 1.29 & 1.53 & 37.35 & 13.02 & 0.93 \\
\hline & & Mols on Canadian & 1.13 & 1.34 & 36.61 & 9.32 & 0.76 \\
\hline & & Molson Golden & 1.08 & 1.28 & 27.04 & 5.93 & 0.72 \\
\hline Overall Mean & 1.89 & & 1.27 & 2.08 & 383.94 & 200.7 & 1.17 \\
\hline
\end{tabular}

a. Variables in Bold font exclude zero from their $95 \%$ credibility interval. 1.00 in the Sub-brand RE term implies the sub-brand is not distinct from the master brand 
Table 5: Brand Equity Estimates and Estimated Brand Value

\begin{tabular}{|c|c|c|c|c|c|c|c|}
\hline (1) & $(2)$ & (3) & (4) & (5) & $(6)$ & (7) & $(6)$ \\
\hline Brand & Res Eqty $^{\text {(B RD) }}$ & $\begin{array}{c}\text { Weighted } \\
\text { REM }\end{array}$ & $\begin{array}{l}\text { Revenue } \\
\text { (\$ Mn/Yr) }\end{array}$ & $\begin{array}{l}\text { Revenue \$ } \\
\text { Premium } \\
(\$ \mathbf{M n} / \mathbf{Y r})\end{array}$ & $\begin{array}{l}\text { AdSpend } \\
(\mathbf{M n} / \mathbf{Y r})\end{array}$ & $\begin{array}{l}\text { Es timated brand value } \\
\text { in the US Market } \\
(\$ \mathbf{M n})\end{array}$ & $\begin{array}{c}\text { Estimated } \\
\text { Brand Value } \\
\text { \$Bn in the US* }\end{array}$ \\
\hline Budweis er & 1.97 & 2.55 & 1620.5 & 985.5 & 267.1 & 8670.0 & 8.1 \\
\hline Miller & 1.19 & 1.78 & 792.8 & 348.3 & 192.4 & 3147.6 & 2.56 \\
\hline Coors & 2.16 & 3.94 & 492.4 & 367.3 & 147.5 & 2977.3 & 2.54 \\
\hline Corona & 3.41 & 4.86 & 475.4 & 377.5 & 43.1 & 4144.9 & 3.08 \\
\hline Michelob & 1.32 & 1.53 & 327.2 & 112.9 & 73.9 & 590.0 & 1.32 \\
\hline Busch & 1.65 & 1.62 & 294.7 & 112.7 & 12.3 & 1160.0 & 1.76 \\
\hline Natural & 1.02 & 1.46 & 265.7 & 83.5 & 0.1 & 940.0 & 1.47 \\
\hline Heineken & 2.16 & 2.10 & 227.5 & 119.4 & 50.4 & 943.1 & 1.59 \\
\hline Milwaukee's Best & 1.01 & 1.35 & 176.3 & 45.4 & 0.0 & 753.2 & 0.54 \\
\hline Keystone & 1.01 & 1.85 & 79.1 & 36.3 & 2.4 & 415.5 & 0.4 \\
\hline Sam Adams & 1.65 & 2.45 & 72.9 & 43.2 & 29.3 & 231.2 & 0.39 \\
\hline Tecate & 1.12 & 1.18 & 69.5 & 10.8 & 2.7 & 103.2 & 0.13 \\
\hline Icehouse & 1.10 & 1.10 & 58.0 & 5.6 & 1.8 & 68.6 & 0.21 \\
\hline Labatt* & 1.12 & 1.12 & 54.7 & 6.0 & $0^{*}$ & 72.7 & 0.12 \\
\hline Becks & 1.32 & 1.45 & 50.6 & 15.6 & 9.1 & 98.0 & 0.16 \\
\hline Old Milwaukee & 1.19 & 1.30 & 44.5 & 10.4 & 0.1 & 124.8 & 0.14 \\
\hline Rolling Rock & 1.32 & 1.37 & 42.6 & 11.6 & 5.3 & 87.6 & 0.2 \\
\hline Amstel Light & 3.40 & 3.40 & 40.4 & 28.5 & 21.1 & 135.4 & 0.13 \\
\hline Fosters & 5.11 & 5.28 & 34.8 & 28.2 & 5.9 & 282.7 & 0.17 \\
\hline Pabst & 1.33 & 1.41 & 34.3 & 10.0 & 0.3 & 117.3 & 0.06 \\
\hline George Killians IR & 1.19 & 1.18 & 30.1 & 4.6 & 0.0 & 56.4 & 0.18 \\
\hline Dos Equis & 1.12 & 1.69 & 29.8 & 12.2 & 4.7 & 100.9 & 0.17 \\
\hline Modelo Especial & 1.32 & 1.37 & 29.1 & 7.9 & 1.7 & 79.6 & 0.09 \\
\hline Pacifico Clara & 7.01 & 7.10 & 27.9 & 24.0 & 1.7 & 273.5 & 0.15 \\
\hline Molson Canadian & 1.19 & 1.43 & 25.3 & 7.6 & 3.6 & 56.1 & 0.13 \\
\hline Simple Average & 1.89 & 2.24 & 215.84 & 112.59 & 36.51 & 1025.18 & 1.03 \\
\hline
\end{tabular}

Brands are sorted descending by revenue within each cluster.

- Values are indicative only 
Table 6: Brand Valuation using Revenue Dollar Premium Estimates

\begin{tabular}{|c|c|c|c|}
\hline Des cription & $\begin{array}{r}\text { Miller } \\
\text { Bewing Co. } \\
\end{array}$ & $\begin{array}{r}\text { Budweis er } \\
\text { brand }\end{array}$ & Source \\
\hline $\begin{array}{l}\text { Financial Valuation } \\
\text { (\$ Billion) }\end{array}$ & 4.25 & 11.93 & SEC, Bus ines s week, Interbrand \\
\hline \multirow[b]{4}{*}{ Adjust for sales from other channels $\sim 12 \%$} & 1591.7 & 3931.3 & \multirow{2}{*}{ Collated from Table 5} \\
\hline & 397.9 & 982.8 & \\
\hline & 318.3 & 786.3 & Margin data from one Regional Grocery Chain \\
\hline & 361.8 & 893.5 & AC Nielsen \\
\hline $\begin{array}{r}\text { Adjust for consumption On-premise at } \\
\sim 25 \% \text { of total retail volume }\end{array}$ & 482.3 & 1191.3 & Adam's Beer Handbook \\
\hline $\begin{array}{r}\text { Contribution from other brands in the } \\
\text { portfolio }\end{array}$ & 507.7 & 1191.3 & $\begin{array}{r}5 \% \text { for the Miller Brewing Co. and inapplicable for } \\
\text { Budweiser }\end{array}$ \\
\hline \multirow{2}{*}{$\begin{array}{r}\text { Ad-spend per year in \$Mn } \\
\text { Remove annual adspend from Revenue } \\
\text { dollar premium }\end{array}$} & 194.2 & 267.1 & $\begin{array}{r}\text { Leading National Advertisiers; } \\
\text { Adams Beer handbook }\end{array}$ \\
\hline & 313.5 & 924.2 & Advertising effect assumed contemporaneous \\
\hline $\begin{array}{r}\text { Adjust for Sales in non-US markets, } \\
11 \% \& 35 \% \text { respectively }\end{array}$ & 352.3 & 1379.4 & $\begin{array}{r}\text { Adam's Beer Handbook, } \\
\text { Company Annual reports }\end{array}$ \\
\hline $\begin{array}{r}\text { NPV Discount rate } \\
\text { at } 7.3 \% \& 10.7 \% \text { respectively }\end{array}$ & 4825.7 & 12891.6 & $\begin{array}{r}\text { SEC filing by SAB in 2002; Calculated using } \\
\text { Anheuser-Busch's Stock Beta }\end{array}$ \\
\hline $\begin{array}{l}\text { Estimated Valuation Figures } \\
\text { (\$ Billion) }\end{array}$ & 4.83 & 12.89 & \\
\hline $\begin{array}{r}\% \text { Discrepancy with } \\
\text { External Brand Values }\end{array}$ & $13.5 \%$ & $8.1 \%$ & \\
\hline
\end{tabular}

a. Figures added up across all Miller brewing brands (Miller, Icehouse \& Milwaukee's Best) 
Figure 1: Distribution of the posterior means of the ResEqty and log ResEqty or $\xi$ Values

(a) Log of ResEqty (Brand)

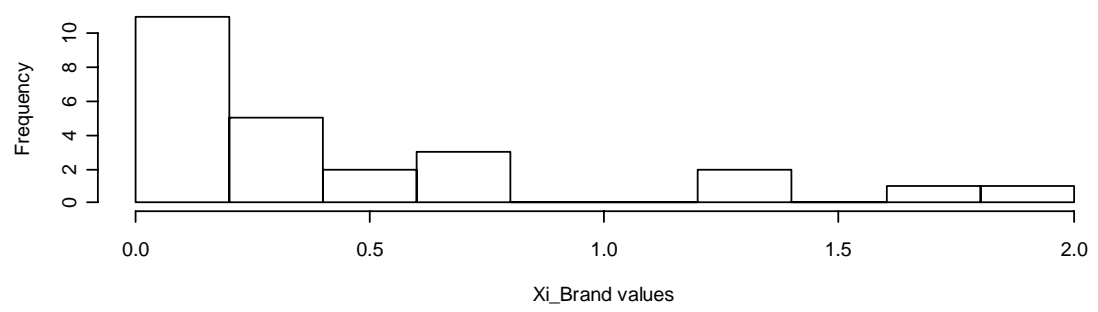

(c) Log of ResEqty (Sub-brand)

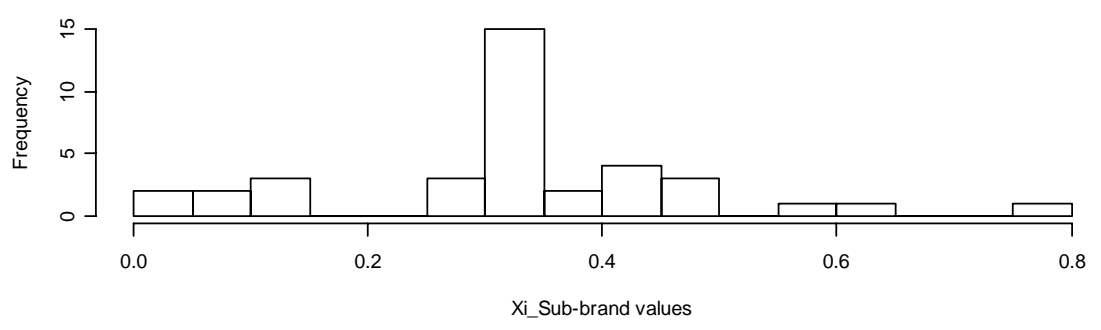

(e) Log of ResEffects (SKU)

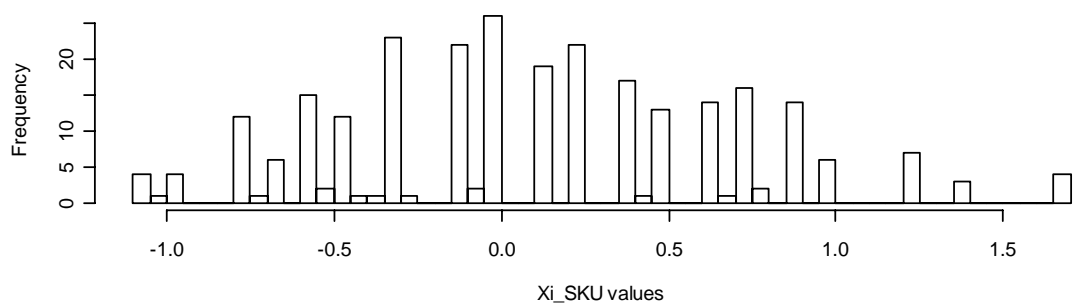

(b) ResEqty (Brand)

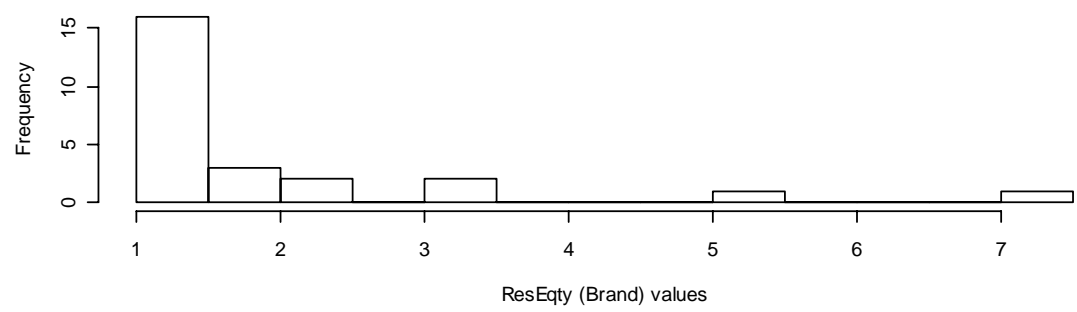

(d) ResEqty (Sub-brand)

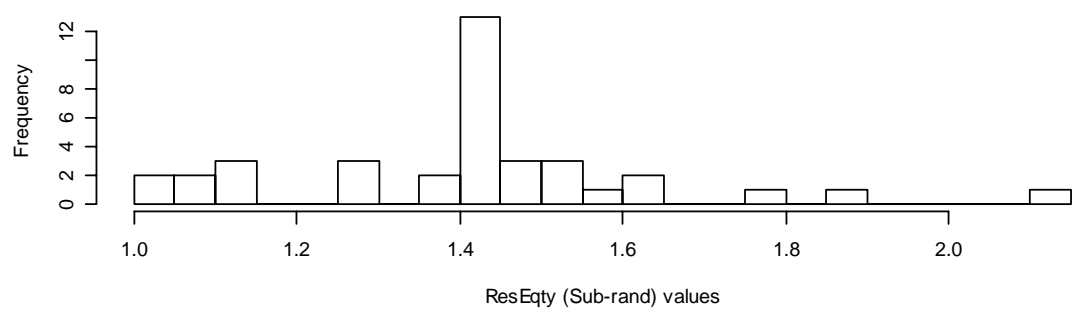

(f) ResEffects (SKU)

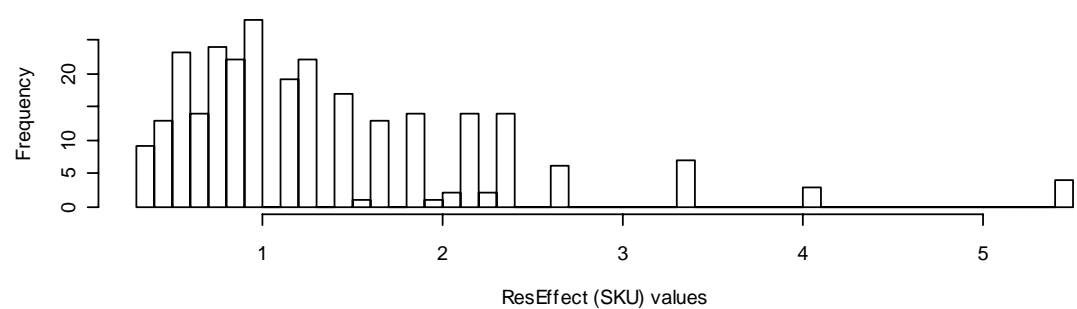




\section{Figure 2: Marginal Posterior Densities of Brand ResEqty for 16 Major Brands}

(1) Bud Light

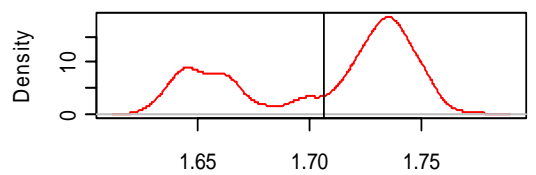

$N=10000$ Bandwidth $=0.005645$

( 5 ) Miller High Life

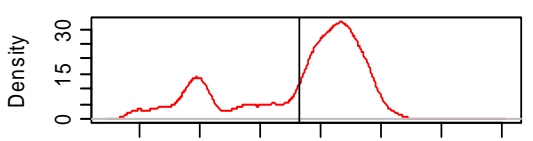

$\begin{array}{lllllll}1.44 & 1.46 & 1.48 & 1.50 & 1.52 & 1.54 & 1.56\end{array}$

$\mathrm{N}=10000$ Bandwidth $=0.003164$

( 9 ) Molson Canadian

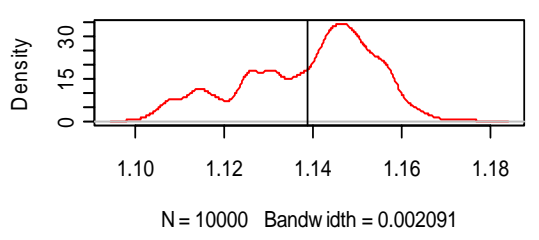

(13) Michelob Ultra Light

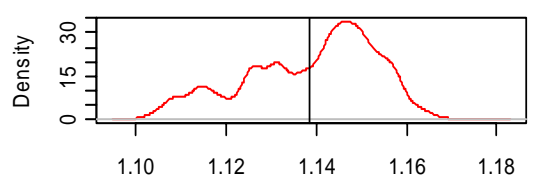

$\mathrm{N}=10000$ Bandw idth $=0.002054$
(2) Bud Ice

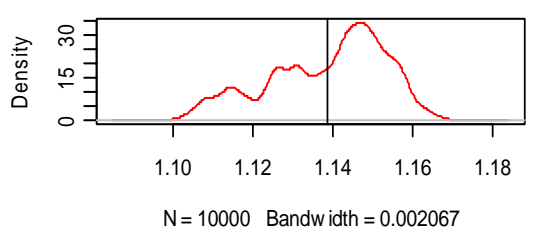

(6) Miller Lite

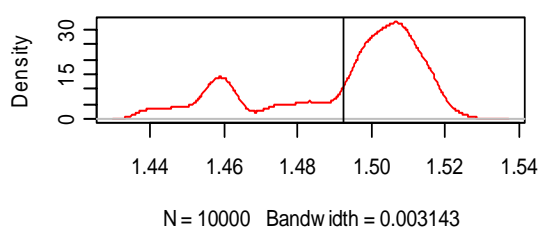

( 10 ) Coors Light

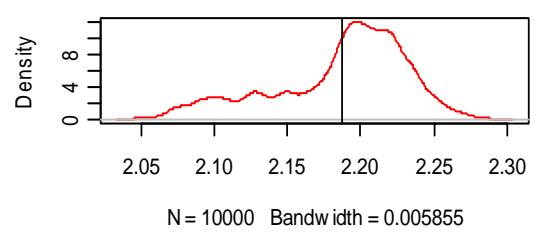

( 14 ) Milwaukee's Best Ice

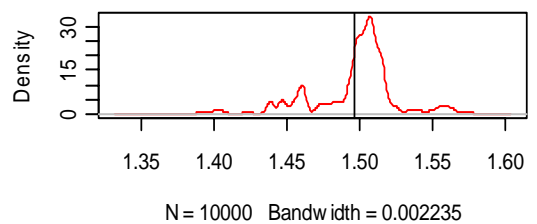

(3) Bud Dry

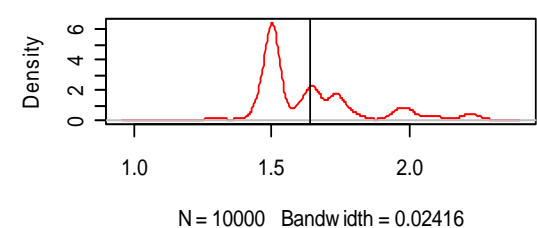

( 7 ) Pabst Draft

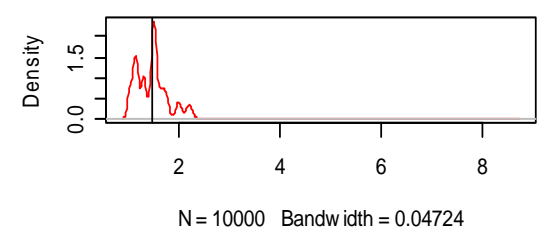

(11) Corona Extra

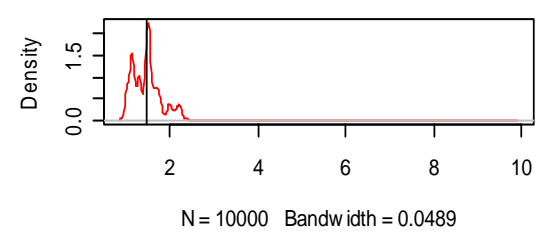

( 15 ) Milwaukee's Best Light

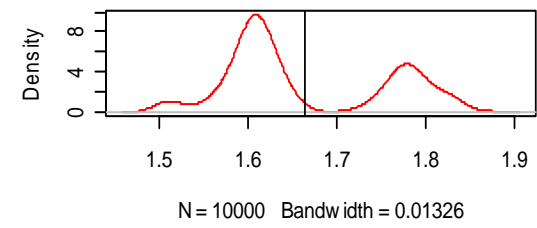

(4) Miller Genuine Draft

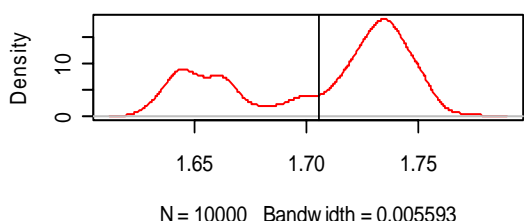

( 8 ) Sam Adams Boston Lager

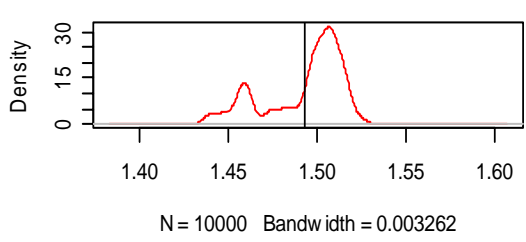

(12) Naural Light

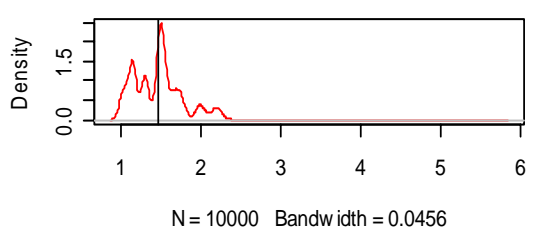

( 16 ) Keystone Light

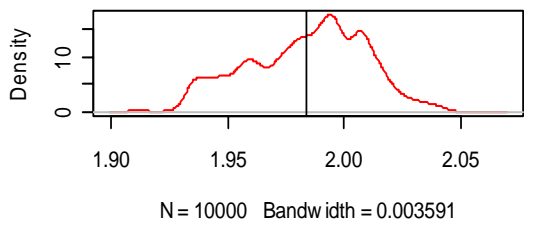




\section{Figure 3: Marginal Posterior densities of Sub-brand ResEqty for 16 Major Sub-brands}

(1) Bud Ice Light

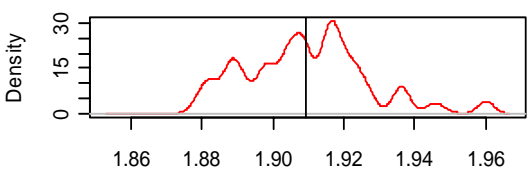

$\mathrm{N}=10000$ Bandwidth $=0.002235$

( 5 ) Miller Genuine Draft

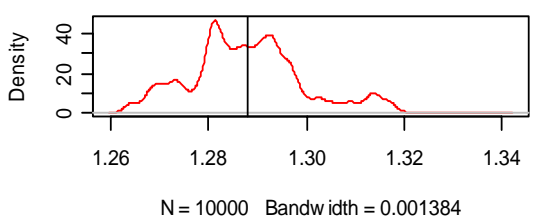

( 9 ) Michelob Ultra Light

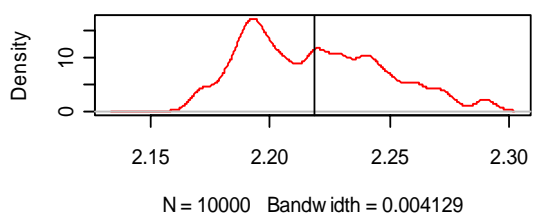

(13) Miller High Life Light

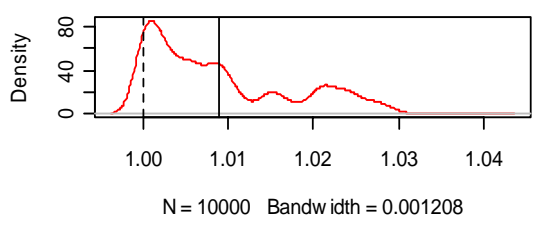

(2) Miller Genuine Draft Light

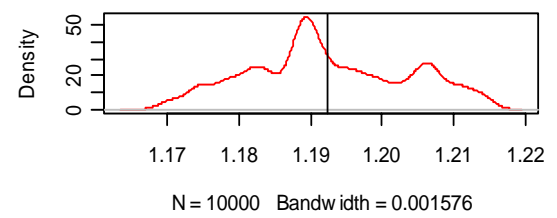

(6) Bud Light

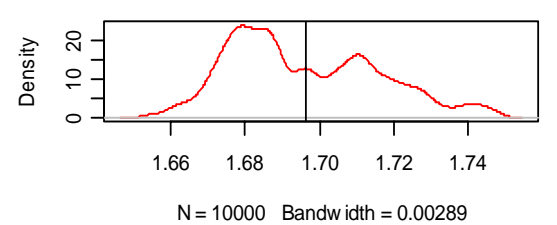

(10) Dos Equis Special Lager

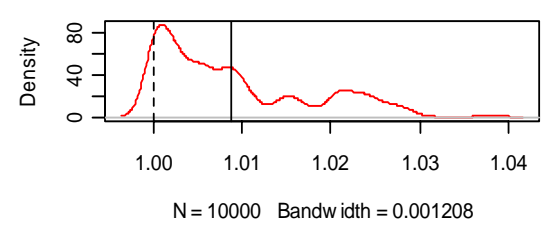

(14) Miller Lite

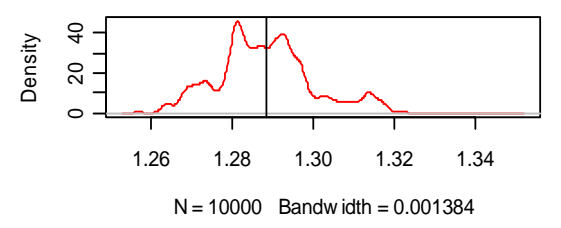

(3) Old Milwaukee Light

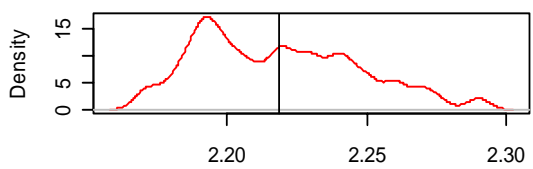

$\mathrm{N}=10000$ Bandwidth $=0.004123$

( 7 ) Bud Dry

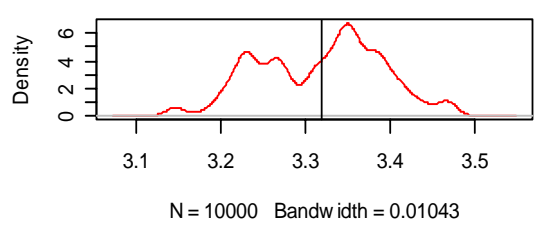

( 11 ) Michelob Honey Lager

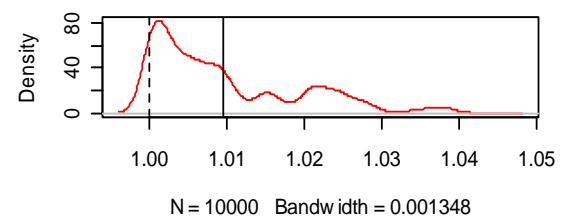

( 15 ) Becks Dark

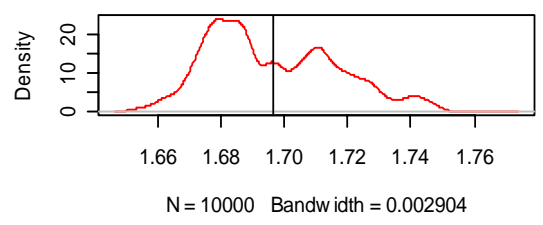

(4) Michelob Amber Bock

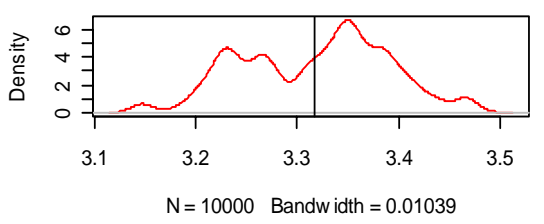

( 8 ) Bud Ice

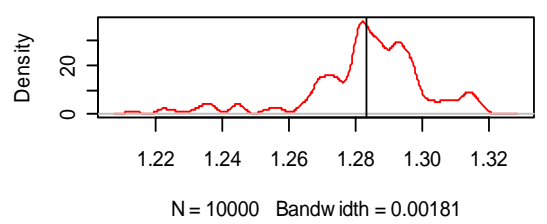

( 12 ) Miller High Life

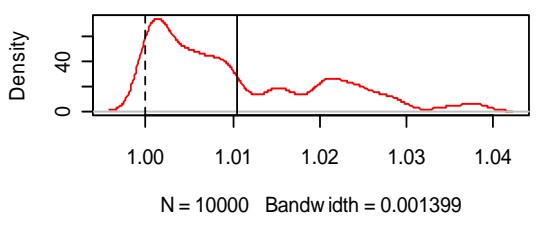

(16) Heineken Dark

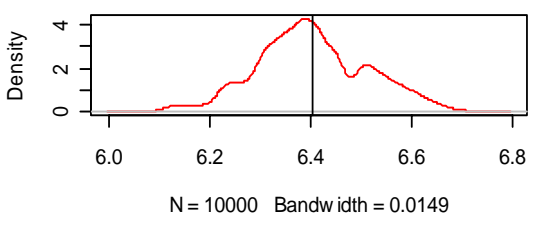




\section{Appendix A: About the Dirichlet Process Mixture Model}

The model in (16) can be written in hierarchical form as:

$$
\begin{aligned}
& \operatorname{Ln}\left(Y_{j t} \mid\{\boldsymbol{\mu}\},\{\xi\}, \text { DATA }\right) \sim N\left(\mu_{0}+\text { DATA } \mu+\{\xi\}, \sigma_{e}^{2}\right), \\
& \{\boldsymbol{\mu}\} \sim \operatorname{MVN}\left(\{\bar{\mu}\}, \Sigma_{\mu}\right), \\
& \xi_{j}^{(S K U)} \mid G_{1} \sim \operatorname{iid} G_{1}, \quad j=1,2, \ldots, J, \\
& G_{1} \mid \alpha_{01}, G_{01} \sim D P\left(\alpha_{01}, G_{01}\right) \\
& \alpha_{01} \sim \operatorname{Uniform}(0.3,1) \\
& G_{01} \sim N\left(0, \sigma_{S K U}^{2}\right), \\
& \sigma_{S K U}^{2} \sim \operatorname{Gamma}\left(a_{S K U}, b_{S K U}\right) .
\end{aligned}
$$

Likewise, for $\xi_{v}^{(S B)}$ and $\xi_{b}^{(B R D)}$ in:

$$
\begin{aligned}
& \xi_{v}^{(S B)} \mid G_{2} \sim \operatorname{iid} G_{2}, \quad v=1,2, \ldots, V, \\
& \xi_{b}^{(B R D)} \mid G_{3} \sim \operatorname{iid} G_{3}, \quad b=1,2, \ldots, B .
\end{aligned}
$$

Let $Z$ denote random quantities of interest such as $\xi_{v}^{(S B)}$ and $\xi_{b}^{(B R D)}$. The unknown distribution $G$ over $Z$ is a random distribution that can be written using the finite approximation (Ishwaran and Zarepour, 2002) of an infinite sum representation of a Dirichlet Process (Ferguson, 1973) as:

$$
\begin{aligned}
& \mathrm{z}_{b} \sim G(Z), \\
& G \mid \alpha, G_{0} \sim G_{L}(.), \\
& \text { where } G_{L}(.)=\sum_{l=1}^{L} p_{l} \delta_{\phi_{l}}(.) .
\end{aligned}
$$

Here: $G_{L}()=.\sum_{l=1}^{L} p_{l} \delta_{\phi_{l}}()=$. a random probability measure based on some number of mixture components $L$ which may potentially be as large as $B ; \mathbf{p}=$ vector of probabilities drawn from a Dirichlet distribution thus: $\mathbf{p}=\left(p_{1}, p_{2}, \ldots, p_{L}\right) \sim$ Dirichlet $\left(\frac{\alpha}{L}, \frac{\alpha}{L}, \ldots \frac{\alpha}{L}\right)$ and constructed using a 'stick-breaking' process (Sethuraman, 1994) that can be described thus: 


$$
\begin{aligned}
& p_{l}=\pi_{l} \prod_{s=1}^{l-1}\left(1-\pi_{s}\right), \\
& \pi_{l} \sim \operatorname{Beta}\left(1, \alpha_{01}\right), \quad l=1, \ldots L-1, \\
& \pi_{L}=1 .
\end{aligned}
$$

In (A.3), $\delta_{\phi_{l}}(u)=$ the unit point mass for some $u$ at $u=\phi_{l}$. The $\phi_{l}$ for $l=1,2, . . L$ are IID variables with some known base distribution $G_{0}$, which is independent of $\mathbf{p}$.

It is known (Ishwaran and Zarepour, 2002; Neal, 2000) that as $L \rightarrow \infty, G_{L}($.$) converges to a$ Dirichlet process $D P\left(\alpha, G_{0}\right)$, where $\alpha$ is the total mass of precision and $G_{0}$ is the prior expectation of $G$. The total mass parameter $\alpha$ a priori controls variation in $G$. The larger the $\alpha$, the closer $G$ will tend to be to $G_{0}$. This brings in much needed robustness in the modeling of $\xi^{(S B)}$ and $\xi^{(B R D)}$. Finally, for $G_{0}$, we place diffuse, independent half-normal $\left(N^{+}\right)$hyperpriors. 